\title{
A novel ferronucleoside that targets DNA replication in pancreatic cancer cells
}

\section{Marium Rana}

University of Birmingham

\section{Alessio Perotti}

University of Birmingham

\section{Lucy Bisset}

University of Birmingham

James Smith

University of Birmingham

\section{Emma Lamben}

University of Birmingham

\section{Zahra Khan}

University of Birmingham

Media Ismail

University of Birmingham

Katherine Ellis

University of Birmingham

Katie Armstrong

University of Birmingham

\section{Samantha Hodder}

University of Birmingham

\section{Cosetta Bertoli}

University College London

https://orcid.org/0000-0001-5684-4630

\section{Leticia Meneguello}

University College London

\section{Robertus de Bruin}

University College London https://orcid.org/0000-0001-9957-1409

Joanna Morris

University of Birmingham https://orcid.org/0000-0001-9762-8133

Isolda Romero-Canelon

University of Birmingham

James Tucker

Birmingham University

Nikolas Hodges ( $\sim$ N.HODGES@bham.ac.uk) 


\section{Article}

Keywords: pancreatic ductal adenocarcinoma (PDAC), ferronucleoside, DNA replication

Posted Date: July 22nd, 2021

DOl: https://doi.org/10.21203/rs.3.rs-741964/v1

License: (c) (i) This work is licensed under a Creative Commons Attribution 4.0 International License. Read Full License 


\title{
A novel ferronucleoside that targets DNA replication in pancreatic cancer cells
}

Marium Rana ${ }^{\dagger 1}$, Alessio Perotti ${ }^{\dagger 1}$, Lucy M Bisset ${ }^{1}$, James D Smith ${ }^{1}$, Emma Lamden ${ }^{1}$, Zahra Khan $^{1}$, Media K. Ismail ${ }^{2}$, Katherine Ellis ${ }^{3}$, Katie A Armstrong ${ }^{1}$, Samantha L Hodder ${ }^{1}$, Cosetta Bertoli ${ }^{4}$, Leticia Meneguello ${ }^{4}$, Robertus A.M. de Bruin ${ }^{4}$, Joanna R Morris ${ }^{3}$, Isolda Romero-Canelon ${ }^{5}$, James HR Tucker ${ }^{2}$ and Nikolas J Hodges ${ }^{1 *}$

${ }^{1}$ School of Biosciences, ${ }^{2}$ School of Chemistry, ${ }^{3}$ Institute of Cancer and Genomic Sciences, and ${ }^{5}$ School of Pharmacy, The University of Birmingham, Edgbaston, Birmingham, B15 2TT. ${ }^{4} \mathrm{MRC}$ Laboratory or Molecular Cell Biology, University College London, London, WC1E 6BT, UK

*Corresponding author: N.Hodges@,bham.ac.uk

† Both authors contributed equally to the work

\begin{abstract}
Pancreatic ductal adenocarcinoma (PDAC) is a disease that remains largely refractory to existing treatments including the nucleoside analogue gemcitabine. In the current study we demonstrate that the ferronucleoside $\mathbf{1 -}\left(\boldsymbol{S}, \boldsymbol{R}_{\boldsymbol{p}}\right)$ is cytotoxic in a panel of PDAC cell lines including gemcitabine resistant $\mathrm{MIAPaCa} 2$, with $\mathrm{IC}_{50}$ values comparable to cisplatin.

Biochemical studies show that the mechanism of action is inhibition of DNA-replication, Sphase cell cycle arrest and stalling of DNA-replication forks which were directly observed at single molecule resolution by DNA-fibre fluorography. In agreement with this, transcriptional changes following treatment with $\mathbf{1 -}\left(S, \boldsymbol{R}_{\boldsymbol{p}}\right)$ include activation of three of the four genes (HUS1, RAD1, RAD17) of the 9-1-1 check point complex clamp and two of the three genes $(M R E 11, N B N)$ that form the MRN complex as well as activation of multiple downstream targets. Furthermore, there was evidence of phosphorylation of checkpoint kinases 1 and 2 as well as RPA1 and gamma H2AX, all of which are considered biochemical markers of replication stress. Studies in p53 deficient cell lines showed activation of

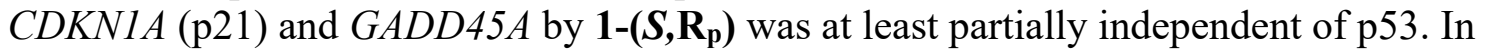
conclusion, because of its potency and activity in gemcitabine resistant cells, $\mathbf{1}-\left(\boldsymbol{S}, \boldsymbol{R}_{\boldsymbol{p}}\right)$ is a promising candidate molecule for development of new treatments for PDAC.
\end{abstract}




\section{Introduction}

Pancreatic ductal adenocarcinoma (PDAC) is a disease with a very poor prognosis. Even when diagnosed early, the 5-year survival rate is less than $10 \%$, the lowest of the 21 most commonly diagnosed cancers in the UK (1). One important factor that contribute to this poor outlook is resistance to existing drugs and a lack of targeted therapies. Single agent chemotherapies using nucleobase derivatives like 5-fluorouracil and nucleoside analogues like gemcitabine were first developed in the 1990s. Since then, progress has been made with the introduction of combination treatments like FOLFOX and FOLFIRONOX (2) and gemcitabine in combination with paclitaxel (3). Although these developments have resulted in modest but significant improvements in patient outcome $(4,5)$, their clinical use is limited because of issues with toxic side effects. The outlook for patients with PDAC remains very poor and there is an urgent need for new compounds with activity in pancreatic cancer.

One strategy to overcome chemo-resistance is to develop new chemical entities distinct from existing clinically used drugs with novel structural features and chemical composition (6). In this respect, metal complexes have proved an attractive starting point for the development of new drugs (7). Exemplars of such a group of compounds that have attracted considerable interest are those based on the organometallic compound ferrocene (8-10), which was shown to have anti-cancer activity as early as the 1980s (11). Since then, ferrocene-based compounds have been investigated for anti-helminthic (12), anti-bacterial (13), anti-fungal (14), anti-malarial (15) and anti-cancer (16) properties. As far as anti-cancer effects are concerned, perhaps the most successful example to date is that of ferrocifen, a ferrocene derivative combining the anti-estrogenic activity of tamoxifen with the cytotoxicity of ferrocene $(8,17,18)$. Studies have shown that ferrocifen and its derivatives not only enhance the activity of tamoxifen in estrogen receptor (ER) positive breast cancer cells, potentially limiting the emergence of tamoxifen resistance but are also toxic to ER receptor negative cells, suggesting ER independent mechanisms of toxicity. Although not fully understood, data suggests that reactive oxygen species (ROS) and a reactive quinone methide metabolite underlie the mechanism of cytotoxicity.

Modification of naturally occurring nucleosides to generate analogues with anti-viral and anti-cancer activities has also been a highly successful strategy in drug discovery as far as organic compounds are concerned (19). Our laboratory is interested in developing new metalcontaining nucleoside analogues containing ferrocene, termed ferronucleosides. In these compounds, the 5-membered cyclopentadienyl ring of ferrocene acts as a bioisostere of the furanose ring in a nucleoside. We have developed compound $\mathbf{1 -}\left(\boldsymbol{S}, \boldsymbol{R}_{\mathbf{p}}\right)$, which contains both a thymine nucleobase and a hydroxy alkyl moiety linked to a ferrocene unit (20), making it chemically distinct from both 5-fluorouracil and gemcitabine. We have already shown that 1$\left(\boldsymbol{S}, \boldsymbol{R}_{\boldsymbol{p}}\right)$ has activity in a panel of cancer cell lines including those derived from the gastrointestinal tract, with $\mathrm{IC}_{50}$ values comparable to cisplatin $(20,21)$. Here we show that 1$\left(\boldsymbol{S}, \boldsymbol{R}_{\boldsymbol{p}}\right)$ also has potent activity in multiple PDAC cell lines, including gemcitabine resistant MIAPaCa2 cells. Mechanistic, biochemical and gene-expression studies demonstrate that the mode of action of $\mathbf{1 -}\left(\boldsymbol{S}, \boldsymbol{R}_{\boldsymbol{p}}\right)$ is distinct from gemcitabine, involving inhibition of DNAreplication without incorporation into DNA. Subsequently, 1-(S, $\left.\boldsymbol{R}_{\boldsymbol{p}}\right)$ causes induction of single stranded DNA-breaks in newly synthesised DNA, resulting in replication fork stress, S-phase arrest and apoptosis. We conclude that because of its potency, activity in gemcitabine resistant cells and novel mode of action, $\mathbf{1 -}\left(\boldsymbol{S}, \boldsymbol{R}_{\boldsymbol{p}}\right)$ is a promising candidate molecule for development of new treatments for PDAC. 


\section{Results}

\section{1- $\left(S, R_{p}\right)$ cytotoxicity in PDAC cell lines is comparable to cisplatin}

The ferronucleoside $\left(S, R_{\mathrm{p}}\right)$-1-[ $\alpha$-Methyl-(3-(hydroxy)propyl)]-2-[(thyminyl)ethyl]-ferrocene, herein referred to as $\mathbf{1}-\left(\boldsymbol{S}, \boldsymbol{R}_{\boldsymbol{p}}\right)$ (Figure 1A) was synthesised as described previously (20). Chiral purity of $1-\left(S, \boldsymbol{R}_{p}\right)$ was confirmed by HPLC (Figure S1). The MTT assay was used to

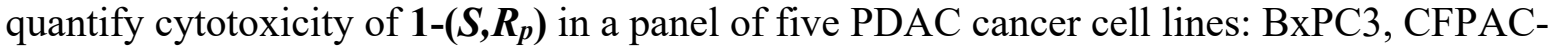
1, PANC-1, MIAPaCa2 and a gemcitabine resistance sub clone of MIAPaCa2. The activity of 1-(S, $\left.\boldsymbol{R}_{\boldsymbol{p}}\right)$ was compared to gemcitabine, used to treat PDAC since its approval by the FDA in 1996 (22) and cisplatin, a reference metallo-drug used to treat a range of solid neoplasms (23). 1-(S, $\left.\boldsymbol{R}_{\boldsymbol{p}}\right)$ was cytotoxic to all five PDAC cell lines investigated with calculated $\mathrm{IC}_{50}$ values of 2.9, 3.7, 2.7, 3.7 and $6.8 \mu \mathrm{M}$ in MIAPaCa2, MIAPaCa2-GemR, BxPC3, CFPAC-1 and PANC-1 cell lines respectively (Figure 1B and C) In contrast we have shown previously that $\mathbf{1}-\left(\boldsymbol{S}, \boldsymbol{R}_{\boldsymbol{p}}\right)$ is not toxic to normal human embryonic lung cells (20). An important finding was there being no statistically significant difference between the $\mathrm{IC}_{50}$ value of $\mathbf{1 -}\left(\boldsymbol{S}, \boldsymbol{R}_{\boldsymbol{p}}\right)$ in $\mathrm{MiaPaCa} 2$ and gemcitabine resistant MIAPaCa2 cells. The potency of $\mathbf{1 -}\left(\boldsymbol{S}, \boldsymbol{R}_{\boldsymbol{p}}\right)$ was lower than that of gemcitabine which had $\mathrm{IC}_{50}$ values in the $\mathrm{nM}$ range for all cell lines tested except gemcitabine resistant MIAPaCa2 (Figure 1D). However, in all cell lines tested, the $\mathrm{IC}_{50}$ value of $1-\left(S, R_{p}\right)$ was comparable with and in some cases superior to that of cisplatin which were 4.6, 1.2, 1.0, 4.9 and 4.5 $\mu \mathrm{M}$ in MiaPaCa2, MIAPaCa2-GemR, BxPC3, CFPAC-1 and PANC-1 cell lines respectively (Figure 1D). Analysis by flow cytometry using annexin- and PI-staining confirmed that the mechanism of cell death in MIAPaCa2 cells is apoptosis (Figure S2).

\section{1- $\left(S, R_{p}\right)$ arrests cancer cells in S-phase and inhibits DNA-replication}

Next, we investigated the effect of $\mathbf{1}-\left(\boldsymbol{S}, \boldsymbol{R}_{\boldsymbol{p}}\right)$ on parameters related to cell cycle progression and DNA-replication. As assessed by propidium iodide labelling, treatment of MIAPaCa2 cells with 1-(S, $\left.\boldsymbol{R}_{\boldsymbol{p}}\right)(0-5 \mu \mathrm{M}, 24$ hours) resulted in a profound accumulation of cells in the Sphase of the cell cycle (Figure 2A). The percentage of cells in S-phase were 29 $\pm 2.0,36 \pm 1.2$, $43 \pm 3.3,50.0 \pm 2.2$ and $66.0 \pm 3.2 \%$ following treatment with $0,0.25,0.5,1.25$ and $5 \mu \mathrm{M} 1-$ $\left(\boldsymbol{S}, \boldsymbol{R}_{\boldsymbol{p}}\right)$ respectively (Figure $\left.2 \mathrm{~B}\right)$. This effect was concentration-dependent and statistically significant at all concentrations investigated $(P<0.001,2$-way ANOVA followed by Dunnett's multiple comparison testing). As a positive control, cells were treated with gemcitabine $(0.5 \mu \mathrm{M}, 24$ hours) which resulted in an accumulation of cells in G1 phase of the cell cycle: $67.0 \pm 1.5 \%$ compared to $44.9 \pm 2.4 \%$ in untreated controls (Figure $2 \mathrm{~B}$ ).

To gain further insight into the mechanism of accumulation of cells in S-phase, rates of DNA-replication and cell division were quantified by labelling cells with EdU and CellTrace

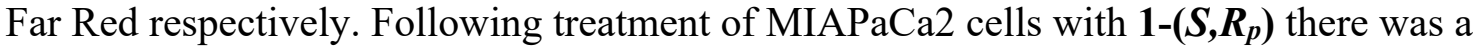
statistically significant concentration-dependent decrease in the median EdU fluorescence labelling of cells $\left(P<0.001,1\right.$-way ANOVA) following treatment of cells with $\mathbf{1}-\left(\boldsymbol{S}, \boldsymbol{R}_{\boldsymbol{p}}\right)$ (Figure 3A). Median fluorescence values were 1418 $\pm 73,1005 \pm 74,762 \pm 69$ and $603 \pm 84$ following treatment with $0,1,2.5$ and $5 \mu \mathrm{M} \mathbf{1}-\left(\boldsymbol{S}, \boldsymbol{R}_{\boldsymbol{p}}\right)$ respectively. Interestingly, although median EdU labelling decreased following treatment with $\mathbf{1 -}\left(\boldsymbol{S}, \boldsymbol{R}_{\boldsymbol{p}}\right)$, the number of cells actively incorporating EdU increased statistically significantly $(P<0.001,2$-way ANOVA followed by Dunnett's multiple comparison testing) increased in a concentration-dependent manner (Figure 3B and 3C). Together, these data suggest that following treatment of cells with 1-(S, $\left.\boldsymbol{R}_{p}\right)$, cells accumulate in S-phase due to inefficient replication of genomic DNA and an increased residence in this phase of the cell cycle. This was further confirmed by confocal 
microscopy analysis where it was observed that control cells were either strongly labelled with EdU or almost completely unlabelled. In contrast, in cells treated with $\mathbf{1}-\left(\boldsymbol{S}, \boldsymbol{R}_{\boldsymbol{p}}\right)$, the overall level of EdU labelling in individual cells was reduced but a higher proportion of cells were labelled (Figure 3D). To further confirm that $\mathbf{1}-\left(\boldsymbol{S}, \boldsymbol{R}_{\boldsymbol{p}}\right)$ inhibits cell and genomic DNA replication, cells were pulse labelled with CellTrace Far Red prior to treatment with 1-(S, $\left.\boldsymbol{R}_{\boldsymbol{p}}\right)$ $(0-5 \mu \mathrm{M})$ for 72 hours. As shown in Figure $3 \mathrm{E}$ and $3 \mathrm{~F}$, there was a statistically significant increase $(\mathrm{P}<0.001)$ in intensity of labelling of cells with CellTrace Far Red compared to controls in a concentration-dependent manner with a calculated $\mathrm{EC}_{50}$ of $1.3 \mu \mathrm{M}(95 \% \mathrm{CI} 0.9$ $1.9 \mu \mathrm{M})$ confirming that $\mathbf{1}-\left(\boldsymbol{S}, \boldsymbol{R}_{\boldsymbol{p}}\right)$ inhibits cellular division, preventing dilution of the CellTrace label into newly replicated cells. Together these data suggest that the activity of 1$\left(\boldsymbol{S}, \boldsymbol{R}_{\boldsymbol{p}}\right)$ involves a specific interaction with a cellular target related to DNA-replication. Further evidence that interaction with genomic DNA is a major mode of $\mathbf{1 -}\left(\boldsymbol{S}, \boldsymbol{R}_{\boldsymbol{p}}\right)$ action was apparent from COMPARE analysis of the one-dose data obtained in the NCI60 panel of cancer cell lines. Out of the 29 compounds identified as having a similar (Pearson's

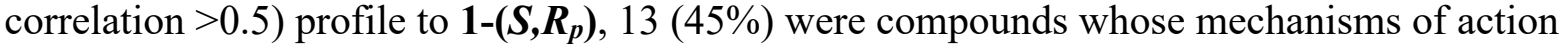
was alkylation of guanine, 7 (24\%) were compounds identified as inhibiting DNA synthesis and $3(10 \%)$ were topoisomerase inhibitors. Interestingly, 4 out of the top 6 correlations $(66 \%)$ had inhibition of DNA-synthesis as the identified mode of action Table S1.

\section{Transcriptomic profiling}

To further study the mechanism of action of $\mathbf{1 -}\left(\boldsymbol{S}, \boldsymbol{R}_{\boldsymbol{p}}\right)$ in pancreatic ductal adenocarcinoma cells we used qPCR targeted at transcripts involved in cellular DNA-damage response and signalling pathways. Of the 84 genes investigated 53 (63\%) were upregulated more than twofold in MIAPaCa2 cells treated with $\mathbf{1 -}\left(\boldsymbol{S}, \boldsymbol{R}_{\boldsymbol{p}}\right)(10 \mu \mathrm{M}, 24$ hours $)$ compared to untreated controls. Of these, 39 genes were statistically significantly upregulated $(\mathrm{P}<0.05)$ confirming that $1-\left(S, R_{p}\right)$ induces a strong transcriptional response related to DNA-damage signalling in $\mathrm{MIAPaCa} 2$ cells. The complete list of upregulated genes is shown in Table S2. Statistically significantly changed genes are plotted as fold change change normalised to GAPDH are shown in Figure 4. Statistically significantly changed genes plotted relative to GAPDH as 2$\mathrm{dCq}$ are shown in Figure S3) When the same set of 84 genes were analysed in two other PDAC cell lines (CFPAC-1 and BxPC3) overall, fewer changes in gene expression more than 2-fold were observed $6(7 \%)$ and $9(11 \%)$ respectively. However, interestingly, out of the top 12 most significantly changed genes observed in MIAPaCa2 cells, $9(75 \%)$ genes were also upregulated in either BxPC3, CFPAC-1 or both cell lines (Table S2). Furthermore, out of the 39 genes significantly upregulated in MIAPaCa2 cells $13(33 \%)$ were also induced by at least 1.5 -fold in at least one of the other 2 PDAC cell lines (Table S2).

Kmeans clustering by String network analysis (24) showed that the 39 genes upregulated in $\mathrm{MIAPaCa} 2$ cells clustered into 2 distinct groups (Figure S4). The first group contained transcripts related to DNA-double strand break repair (Reactome pathway HSA-5693532) and DNA repair (Reactome pathway HSA-73894) and included the following genes $R A D 17$, RAD1, HUS1, NBN, MRE11A, CHEK1, CHEK2, RBBP8, ATM, BRCA1 and MAD2L2. The second cluster contained transcripts related to G1/S transition (Reactome pathway HSA69206), S-phase (Reactome pathway HSA-69242) and Mitotic G1-G1/S phase ((Reactome pathway HSA-453279) and contained the genes $C D K 1, C D K 7, M C M 3, C D C 6, C D C 16$, CCNE1, CCND2, TFDP1, DP2, SKP2, RB1, CDK2, RBL2 and CDKN1A. Functional annotation analysis of significantly upregulated genes in DAVID revealed statistically significant (Benjamini corrected $P$ values $<0.0001$ ) over-representation of genes from the following BIOCARTA pathways: ATM signalling pathway (11/21 genes), Role of BRCA1, BRCA2 and ATR in cancer susceptibility (11/16), cell cycle $(8 / 25)$, cyclins and cell cycle regulation $(8 / 25)$, p53 signalling pathway $(7 / 17)$ and cell cycle $(8 / 30)$. Together these data 


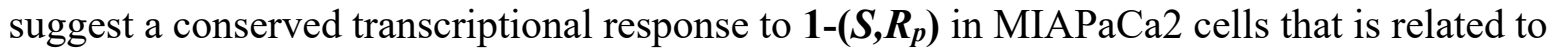
DNA-damage response and S-phase arrest.

To gain further insight into the core transcriptional response of PDAC cells to 1-(S, $\left.\boldsymbol{R}_{\boldsymbol{p}}\right)$ we analysed the 13 significantly upregulated genes in MIAPaCa2 cells that were also upregulated in at least one of the other 2 cell lines investigated (CFPAC-1 and BxPC3). Analysis of the 13 genes showed strong evidence of molecular interactions. Within the 13 nodes of the network, the number of edges was 22 and the average local clustering coefficient was 0.588 and had a PPI enrichment value $<1.0 \mathrm{e}-16$. As shown in Figure 5A, within the network major GO-terms represented included: GO:0051726 regulation of cell cycle (coloured red), GO:0045786 negative regulation of cell cycle (coloured blue) and GO:0006974 cellular response to DNA damage stimulus (coloured green). The top 10 significantly functionally enriched GO terms in the network are shown in Table 1 . Together, these data strongly suggest that the underlying mechanism of response to $\mathbf{1 -}\left(\boldsymbol{S}, \boldsymbol{R}_{\boldsymbol{p}}\right)$ is the same in all three PDAC cell lines investigated and related to DNA-replication fork stress, DNA damage response and cell cycle perturbation. To validate the changes in gene expression of the 13 genes common to the three cell lines we quantified them by qPCR in MIAPaCa2, CFPAC-1 and BxPC3 PDAC cells lines (Figure 5B).

Interestingly, within the network of 13 genes, 7 (CDK2, MDM2, CASP3, CDKN1A, GADD45A, CCNG2, CCNE1) were identified as being related to p53 signalling (KEGG pathway HSA04115). Of these, four (CDK2, GADD45A, CDKN1A, CCNE1) were also represented in the reactome pathway TP53 regulates transcription of cell cycle genes (HAS6791312) and four (CDK2, MDM2, CDKN1A, CCNE10) in p53-dependent G1 DNA damage response (HSA-69563). Therefore, to study the possible involvement of TP53 in the cellular

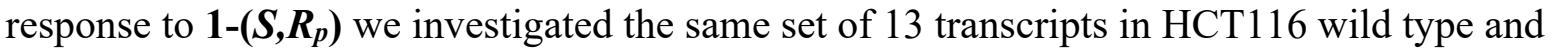
TP53 null cell lines. There was no difference in the observed transcriptional response (Figure $\mathrm{S} 5 \mathrm{~A})$. In contrast, there was a small but statistically significant difference $(\mathrm{P}<0.05)$ in the

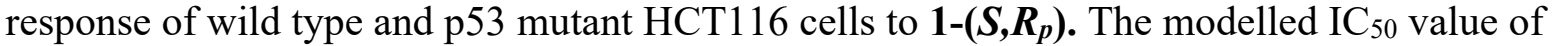
$\mathbf{1 -}\left(\boldsymbol{S}, \boldsymbol{R}_{\boldsymbol{p}}\right)$ in p53 wildtype and null cell lines been $11.9(6.9-20.0)$ and $35.4(21.8-58.9) \mu \mathrm{M}$

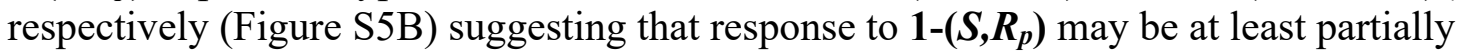
dependent on $\mathrm{p} 53$. To further investigate $\mathrm{p} 53$-independent regulation of $\mathbf{1 -}\left(\boldsymbol{S}, \boldsymbol{R}_{\boldsymbol{p}}\right)$ responsive genes, the expression of the homologues p 63 and p 73 were investigated. Interestingly, treatment of PDAC cells with 1-(S, $\left.\boldsymbol{R}_{\boldsymbol{p}}\right)$ resulted in induction of p73 but not p63 (Figure S6A). Levels of p73 transcript were also upregulated in HCT116 p53 knockout cells (Figure S6B) further supporting a compensatory role for this transcription factor in the response of cells to $1-\left(S, R_{p}\right)$.

\section{1- $\left(S, R_{p}\right)$ induces DNA-strand breaks in newly synthesised genomic DNA}

To investigate whether the cell cycle and transcriptomic changes related to DNA-damage and replication fork stress were manifest as biochemical changes, we quantified the level of single and double DNA-strand breaks in cells using the alkaline comet assay and $\gamma \mathrm{H} 2 \mathrm{AX}$

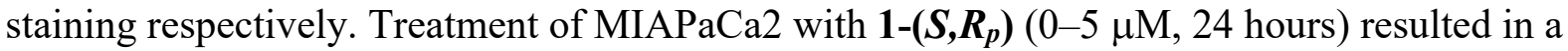
statistically significant $(\mathrm{P}<0.001)$ concentration-dependent increase in the numbers of DNAstrand breaks as assessed by the \% of DNA in the comet tail (Figure 6A). Mean \% Tail DNA values were: $0.38 \pm 0.11,0.93 \pm 0.02,5.90 \pm 1.3$ and $14.2 \pm 1.25 \%$ for cells treated with $0,1,2.5$ and $5 \mu \mathrm{M} \mathbf{1}-\left(\boldsymbol{S}, \boldsymbol{R}_{\boldsymbol{p}}\right)$ respectively. Consistent with previous studies $(25,26)$, gemcitabine $(50$ $\mathrm{nM}, 24$ hours) also induced DNA-strand breaks (Figure 6A). 
Next, to investigate whether 1-(S, $\left.\boldsymbol{R}_{\boldsymbol{p}}\right)$-induced DNA-strand breaks were occurring in newly synthesised DNA, the comet assay was repeated in cells that had been pulse-labelled with the fluorescent base EdU. When cells were treated with 1-(S, $\left.\boldsymbol{R}_{\boldsymbol{p}}\right)(5 \mu \mathrm{M}, 24$ hours) it was clearly apparent that the DNA present in the comet tail was labelled with EdU (Figure 6B) consistent with 1-(S, $\left.\boldsymbol{R}_{\boldsymbol{p}}\right)$ inducing DNA-strand breaks in recently synthesised DNA during replication fork stress. As a negative control, when cells treated with the direct acting genotoxin NQO $(2.1 \mu \mathrm{M}, 24$ hours) there was no evidence of EdU-labelled DNA in the comet tail (Figure $6 \mathrm{~B})$. There was also evidence that treatment of all three PDAC cells lines with $\mathbf{1}-\left(\boldsymbol{S}, \boldsymbol{R}_{\boldsymbol{p}}\right)(10$ $\mu \mathrm{M}, 24$ hours) induced double DNA-strand breaks as assessed by phosphorylation of gammaH2AX using both flow cytometry and confocal microscopy (Figure 7).

\section{1-(S, $\left.R_{p}\right)$ induces replication fork arrest and activation of check point kinases}

To investigate the direct effect on active DNA replication and down-stream signalling events we used single molecule DNA-fibre fluorography to study replication fork dynamics in MIAPaCa2 cells treated with $\mathbf{1 -}\left(\boldsymbol{S}, \boldsymbol{R}_{\boldsymbol{p}}\right)$. Cells were sequentially labelled with CldU and IdU in the presence or absence of compound treatment to monitor active replication forks. Our

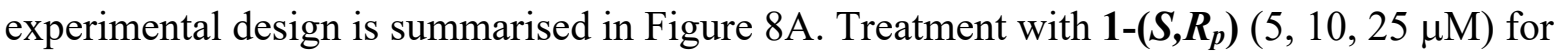
24 hours resulted in concentration-dependent inhibition of DNA-replication and evidence of stalled replication forks. Fibre length in $\mu \mathrm{m}$ was converted to $\mathrm{kB}$ of DNA as described previously (27). In the untreated control MIAPaCa2 cells, mean fibre length was $2.34 \pm 0.8 \mathrm{kB}$ (range $0.73-5.60)$. Cells treated with $\mathbf{1 -}\left(\boldsymbol{S}, \boldsymbol{R}_{\boldsymbol{p}}\right)$ had a statistically significantly shorter fibres (P $<0.001)$. Following treatment with 5 and $10 \mu \mathrm{M} \mathbf{1}-\left(\boldsymbol{S}, \boldsymbol{R}_{\boldsymbol{p}}\right)$ mean fibre lengths were $0.56 \pm 0.20$ (range $0.19-2.17$ ) and $0.28 \pm 0.12$ (range $0.08-1.53$ ) $\mathrm{kB}$ respectively (Figure $8 \mathrm{~B}$ ).

Representative images of DNA-fibres from each experimental condition are shown in Figures 8D-G. Treatment with $25 \mu \mathrm{M} \mathbf{1}-\left(\boldsymbol{S}, \boldsymbol{R}_{\boldsymbol{p}}\right)$ resulted in complete arrest of fibre formation (Figure $8 \mathrm{G})$. As expected, $\mathbf{1}-\left(\boldsymbol{S}, \boldsymbol{R}_{\boldsymbol{p}}\right)$ treatment also resulted in a concentration-dependent decrease in the speed of DNA-replication (Figure 8C). Calculated DNA-replication rates were $0.12 \pm 0.04$, $0.028 \pm 0.01$ and $0.014 \pm 0.006 \mathrm{kB} /$ minute in control, 5 and $10 \mu \mathrm{M}$ treatments respectively. These data confirm the effect of $\mathbf{1 -}\left(\boldsymbol{S}, \boldsymbol{R}_{\boldsymbol{p}}\right)$ on DNA replication as quantified by incorporation of EdU above. Furthermore, consistent with this and the transcriptional changes described above we also observed that $\mathbf{1}-\left(\boldsymbol{S}, \boldsymbol{R}_{\boldsymbol{p}}\right)$ treatment results in phosphorylation of the checkpoint kinases CHEK1 (Ser 345) and CHEK2 (Thr 68), replication protein A (RPA) and gammaH2AX (Ser 139) as assessed by western blotting (Figure S7).

\section{Discussion}

Previously we have shown that $1-\left(S, R_{p}\right)$, a novel nucleoside analogue has cytotoxic activity in multiple cancer cell lines, including those derived from the gastrointestinal tract with a potency comparable to, or in some cases superior to cisplatin (20). In the current study we demonstrate that $\mathbf{1 -}\left(\boldsymbol{S}, \boldsymbol{R}_{\boldsymbol{p}}\right)$ is also cytotoxic to a panel of five pancreatic ductal adenoma carcinoma (PDAC) cell lines including one that is resistant to gemcitabine. We have shown previously that non-phosphorylatable analogues of $\mathbf{1 -}\left(\boldsymbol{S}, \boldsymbol{R}_{\boldsymbol{p}}\right)$ have similar cytotoxicity to the parent compound (28). Therefore, in contrast to other clinically used nucleobase and nucleoside analogues like 5-fluorouracil and gemcitabine respectively, the mechanism of toxicity of $\mathbf{1 -}\left(\boldsymbol{S}, \boldsymbol{R}_{\boldsymbol{p}}\right)$ is independent of substrate phosphorylation and incorporation into genomic DNA. We conclude that the mode of action of $\mathbf{1 -}\left(\boldsymbol{S}, \boldsymbol{R}_{\boldsymbol{p}}\right)$ is novel and distinct from gemcitabine. Structural activity studies have shown that regiochemistry (28) and length of the hydroxy alkyl linker (21) are key determinants of cytotoxicity. This suggests a specific cellular target rather than a non-specific mechanism of toxicity such as redox cycling of the iron and generation of reactive oxygen species, a mechanism which has been suggested for 
both the parent ferrocene compound $(29,30)$ as well as other ferrocene analogues including ferrocifens $(31,32)$ and amino ferrocifens $(33)$. On the other hand, in support of a possible role of redox activity, a ruthenium analogue of $1-\left(S, R_{p}\right)$, which shows less reversible electrochemistry, and whose oxidised form is less accessible in biological systems, is not toxic to the MIAPaCa2 cell line (34). This indicates a role for the iron in the toxicity of 1$\left(\boldsymbol{S}, \boldsymbol{R}_{\boldsymbol{p}}\right)$ and possibly generation of localised redox activity as part of the mechanism of action. Interestingly, DNA polymerases are now known to contain iron-sulfur clusters. Furthermore, it is becoming increasingly apparent that they are involved in redox regulation of polymerase functions $(35,36)$. It is possible therefore, that modification of the local redox environment by $1-\left(S, R_{p}\right)$ affects DNA polymerase activity and that this plays a role in the molecular mode of action. However, we cannot exclude other cellular targets, for example inhibition of DNAtopoisomerase, direct DNA-reactivity or depletion of the nucleotide pool as possible mechanisms of $\mathbf{1 -}\left(\boldsymbol{S}, \boldsymbol{R}_{\boldsymbol{p}}\right)$ toxicity.

In the current study we also show that like 5-fluorouracil (37) and gemcitabine (38), 1-(S, $\left.\boldsymbol{R}_{\boldsymbol{p}}\right)$ has a profound effect on progress of cancer cells through the cell cycle. Specifically, this occurs by causing accumulation of cancer cells in the S-phase of the cell cycle, inhibiting replication of genomic DNA and cell division, which ultimately results in cell death by apoptosis. Analysis in three PDAC cell lines revealed a highly conserved transcriptional response to $1-\left(S, R_{p}\right)$ that is consistent with a mechanism of action related to inhibition of DNA-replication and replication fork stress. One particularly striking change was in expression of transcripts involved in the cellular response to stalled DNA-replication forks. This included three of the four genes (HUS1, RAD1, RAD17) of the 9-1-1 check point complex clamp (39). Previous studies have shown that depletion of either RAD9 (40) or RADI7 (41) sensitises HeLa and PDAC cells respectively to gemcitabine. Furthermore, other studies have identified that both RAD9 and HUS1 play an important role in the sensitivity of pancreatic cancer cells to gemcitabine (40). Together, these data demonstrate the importance of this signalling complex in the cellular response to gemcitabine and suggest that although the mode of action of $\mathbf{1 -}\left(\boldsymbol{S}, \boldsymbol{R}_{\boldsymbol{p}}\right)$ is distinct from gemcitabine DNA-replication stress is still central to the mechanism of action. 1-(S, $\left.\boldsymbol{R}_{p}\right)$ treatment also upregulates two of the three genes $(M R E 11, N B N)$ that form the MRN complex which plays a critical role in sensing DNAdouble strand breaks and initiating double strand break repair by homologous recombination and non-homologous end joining as well as activation of cell cycle checkpoints (42). This complex has also been demonstrated to play an important role in the cellular response to stalled replication forks after treatment of cancer cells with nucleoside analogues including gemcitabine (43). One of the major cellular responses to blocked DNA-synthesis is activation of the S-phase DNA damage response as discussed above and reviewed by Ewald et al (44). This results in inhibition of initiation and firing of replication forks consistent with the observation of S-phase cell cycle arrest and induction of CDK2 following treatment of cells with 1-(S, $\left.\boldsymbol{R}_{p}\right)$.

Single molecule DNA-fibre fluorography experiments showed that $\mathbf{1 -}\left(\boldsymbol{S}, \boldsymbol{R}_{\boldsymbol{p}}\right)$ causes concentration-dependent inhibition of DNA replication. Western blotting confirmed phosphorylation of $\mathrm{CHK} 1$ and $\mathrm{CHK} 2$ checkpoint kinases which are known to be activated in response to DNA-strand breaks and stalled DNA-replication forks. In addition, RPA1 which is also involved in the cellular response to single stranded DNA damage was also phosphorylated. Together these data strongly support our hypothesis that $\mathbf{1 -}\left(\boldsymbol{S}, \boldsymbol{R}_{\boldsymbol{p}}\right)$ stalls DNA-replication forks activating downstream signalling pathways ultimately resulting in $\mathrm{S}$ phase arrest and cell death by apoptosis. 
Consistent with a role for DNA-breaks been important in the mechanism of toxicity of 1$\left(\boldsymbol{S}, \boldsymbol{R}_{p}\right)$, in the current study we show that $\mathbf{1 -}\left(\boldsymbol{S}, \boldsymbol{R}_{\boldsymbol{p}}\right)$ induces both single and double DNAstrand breaks as assessed by the comet assay and $\gamma \mathrm{H} 2 \mathrm{AX}$ phosphorylation. We also show recently synthesised genomic DNA may be specifically targeted. In addition to a marker of double-stranded DNA breaks, it has also been demonstrated that phosphorylation of $\gamma \mathrm{H} 2 \mathrm{AX}$ also occurs in response to stalled DNA-replication forks, including those induced by gemcitabine and this has been linked to S-phase checkpoint activation (25) and recruitment of signalling molecules including MRE11 and RAD51 (45). Previous studies have also shown that the MRN complex also regulates resistance of cancer cells to other nucleoside analogues where it is involved in the cellular response to stalled DNA replication forks, but it was not clear whether this was directly related to DNA-strand breaks or via other mechanisms (43). Many of the genes involved in signalling pathways downstream of the 9-1-1 complex including: ATM, RAD51, BRCA1, BRCA2, CHK1, CHK2 were observed to be transcriptionally activated following treatment of cells with $\mathbf{1}-\left(\boldsymbol{S}, \boldsymbol{R}_{p}\right)$. Furthermore, $\mathbf{1}-\left(\boldsymbol{S}, \boldsymbol{R}_{p}\right)$ results in phosphorylation of both $\mathrm{CHK} 1$ and $\mathrm{CHK} 2$, these changes are summarised in Figure 9. $\mathrm{CHK} 1$ and $\mathrm{CHK} 2$ are critical regulators in the co-ordinated cellular response to DNAdamage and stalled replication forks (46) and are important in the response of cancer cells to gemcitabine. In fact, previous studies have shown that CHK1 kinase inhibitors sensitise pancreatic cancer cells to the toxicity of gemcitabine (47-51), a strategy which has shown promise in clinical trials (52).

Another key transcriptional change observed following treatment of cells with $\mathbf{1 -}\left(\boldsymbol{S}, \boldsymbol{R}_{\boldsymbol{p}}\right)$ is strong induction of both the DNA-damage response protein GADD45A and the cyclindependent kinase inhibitor $C D K N 1 A$ (p21). These observations suggest that $\mathbf{1 -}\left(\boldsymbol{S}, \boldsymbol{R}_{\boldsymbol{p}}\right)$ induces cellular genotoxic stress, consistent with our observation of single and double-DNA strand breaks and S-phase cell cycle arrest following treatment of cells with 1-(S, $\left.\boldsymbol{R}_{\boldsymbol{p}}\right)$. GADD45A has previously been linked to chemoresistance in a number of cancer types including melanoma (53) and glioblastoma (54) but, to the best of our knowledge its role in the response of pancreatic cancer cells to nucleoside analogues has not been evaluated. Both GADD45A and CDKN1A are often considered to be downstream of, and transcriptionally activated by p53 (55). However, all of the PDAC cell lines used in this study contain inactivating mutations in $\mathrm{p} 53$, a fact that was confirmed directly by sequencing. Therefore,

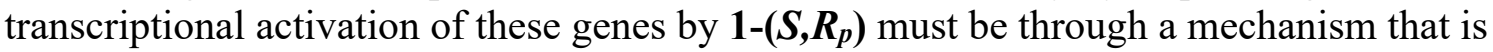
independent of p53. Several possible mechanisms have been reported; indeed, it has been shown that some chemical agents including the alkylating agent methyl methane sulfonate and UV-radiation appear to activate GADD45A via a mechanism that is at least partly p53independent involving the transcription factors Oct-1 and NF-YA (56). Interestingly, overexpression of $G A D D 45 A$ has been linked to a poor prognosis in patients with pancreatic ductal adenocarcinoma, (57) suggesting that this gene is important in PDAC cell phenotype and disease progression.

In the current study, p53 knockout HCT116 cells were marginally less sensitive to $\mathbf{1 - ( S , \boldsymbol { R } _ { \boldsymbol { p } } )}$ compared to wild-type cells, which suggests a role for p53 in the mechanism of toxicity.

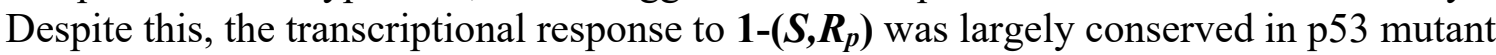
cells. We also showed that p73 (but not p63) homologues of p53 were transcriptionally activated in p53-deficient HCT116 cells and furthermore, that in some of the PDAC cell lines investigated, p73 was also induced following treatment with $\mathbf{1 -}\left(\boldsymbol{S}, \boldsymbol{R}_{\boldsymbol{p}}\right)$. The significance of this result is unclear; $\mathrm{p} 73$ is able to transactivate p53-regulated promoters and there is also evidence that in p53-deficient PDAC cell lines that sensitivity to gemcitabine can be enhanced through mechanisms that are dependent on both p63 and p73 transcription factor 
activity (58-61). However, to the best of our knowledge there is no clear evidence linking p73 to the transcriptional regulation of either GADD45A or CDKN1A. We speculate that in PDAC cell lines, p73 may be able to partially compensate for the lack of p53-dependent induction of $G A D D 45 A$ and $C D K N 1 A$ and that this is important in the cellular response to agents that cause replication fork and genotoxic stress.

\section{Conclusion}

We show that $1-\left(S, R_{p}\right)$ has cytotoxic activity in multiple pancreatic cancer cells and that the mode of action is inhibition of DNA replication resulting in replication fork stress, cell cycle arrest and apoptosis. Our data point to a mechanism of action of $\mathbf{1 -}\left(\boldsymbol{S}, \boldsymbol{R}_{\boldsymbol{p}}\right)$ that is distinct from that of existing compounds like 5-fluorouracil and gemcitabine currently used to treat PDAC. Furthermore, the toxicity and mechanism of action of $\mathbf{1 -}\left(\boldsymbol{S}, \boldsymbol{R}_{\boldsymbol{p}}\right)$ is at least partially independent of p53 transcription factor activity. Cytotoxicity is dependent on both the regio-

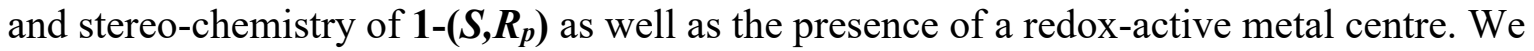
therefore hypothesise that the mechanism of action is through interaction with, and local redox modification of specific cellular targets. Based on the observation of inhibition of DNA-replication, induction of DNA breaks specifically in recently synthesised DNA and replication fork arrest we hypothesise that the cellular target is the DNA-replication machinery itself. In conclusion, because of its novel mode of action, potency and activity in gemcitabine resistant cells $\mathbf{1 -}\left(\boldsymbol{S}, \boldsymbol{R}_{\boldsymbol{p}}\right)$ is a promising candidate molecule for development of new treatments for PDAC.

\section{Materials and Methods}

\section{Cell Culture}

MIAPaCa2 (85062806), BxPC3 (93120816), CFPAC-1 (91112501) and PANC-1 (87092802) pancreatic ductal adenoma cancer cell lines were all purchased from the European Collection of Authenticated Cell Cultures. All of the cell lines studied contain verified homozygous missense substitution mutations in the DNA binding domain of TP53 as catalogued in the COSMIC database of cancer cell lines (https://cancer.sanger.ac.uk/cell lines) as follows: MIAPaCa2 (pR248W, c742 C $\rightarrow$ T), BxPC3 (pY220C, c659 A $\rightarrow$ G), CFPAC-1 (pC242R, $\mathrm{c} 724 \mathrm{~T} \rightarrow \mathrm{C})$ and PANC-1 (pR273H, c818 G $\rightarrow \mathrm{A})$. All of these mutations are classified as non-functional in the IARC TP53 database (http://p53.iarc.fr) based on overall transcriptional activity (TA) using 8 different promoters measured in yeast (62). The presence of published TP53 mutations was confirmed directly by sequencing (Supplementary Information). All cell culture media and supplements were purchased from Gibco (Thermo Scientific), all plasticware was purchased from Greiner Bio-One. All lines were grown in $\mathrm{T}_{75}$ tissue culture flasks as monolayers. MIAPaCa2 cells were cultured in DMEM, supplemented with $10 \%$ (v/v) foetal bovine serum, $100 \mathrm{U} / \mathrm{mL}$ penicillin, $100 \mathrm{mg} / \mathrm{mL}$ streptomycin, and $2 \mathrm{mM} \mathrm{L-}$ glutamine; BxPC3, PANC-1 and CFPAC-1 were cultured in RPMI-1640, supplemented in the same way. All cells were maintained at $37^{\circ} \mathrm{C}$ in a $5 \% \mathrm{CO}_{2}$ humidified incubator and subcultured twice weekly before confluency. All cell cultures were confirmed free from Mycoplasma sp. contamination using the EZ-PCR mycoplasma detection kit according to the manufacturer's instructions. All cells were cultured up to passage 20 before being discarded.

\section{MTT assay}

The MTT (3-(4,5-dimethylthiazol-2-yl)-2,5-diphenyltetrazolium bromide) assay was used to assess cell cytotoxicity (63). Cells were seeded at a density of 5000 cells per well in a 96-well plate, exposed to different concentrations of $\mathbf{1 -}\left(\boldsymbol{S}, \boldsymbol{R}_{\boldsymbol{p}}\right)$ and incubated for 72 hours. MTT was added to a final concentration of $0.5 \mathrm{mg} / \mathrm{mL}$ followed by a 3-hour incubation. DMSO was 
added to solubilise formazan and absorbance was read at $490 \mathrm{~nm}$ in Tecan Infinite F200 Pro (Tecan, Männedorf, Switzerland). Samples were analysed in triplicate technical replicate and each experiment was repeated three times independently.

\section{Gene expression profiling}

Total RNA was extracted from cells using a Qiagen RNeasy Mini Kit and reverse-transcribed using a Qiagen $\mathrm{RT}^{2}$ First Strand Kit according to manufacturer's instructions. Gene expression of 84 key genes related to cell cycle progression and DNA-damage checkpoint were quantified using a Qiagen $\mathrm{RT}^{2}$ Profiler ${ }^{\mathrm{TM}}$ PCR Array Human Cell Cycle PCR array (PAHS-020Z) according to manufacturer's instructions. For MIAPaCa2 cells, the PCR array was carried out in three independent biological replicates. For BxPC3 and CFPAC-1 cells, one biological replicate was undertaken. Results were analysed using the delta delta $\mathrm{Cq}$ method with normalization to $G A P D H$, which was the most stable housekeeping gene across samples. 13 genes (BRCA2, HUS1, RBBP8, SERTAD1, MDM2, GADD45A, CASP3, $C D K N 1 A, C D K 2, C C N G 2, C C N E 1, C D K 7$ and CCNT1) were selected for further validation in all three cells by qPCR. Briefly, brilliant II SYBR ${ }^{\circledR}$ Green QPCR Master Mix (Agilent, Santa Clara, US) and the following the cycling conditions in the kit recommended for Agilent Aria MX. Primers used for each gene of interest are shown in the supplementary materials and methods. B2M was the housekeeping gene of choice used as an internal control.

\section{Comet Assay}

After treatment cells were trypsinized and centrifuged ( $5 \mathrm{~min}, 800 \mathrm{~g}$ ) to remove the culture medium. Cells were then resuspended in $90 \mu \mathrm{L}$ low melting agarose $0.7 \%$ (LMA) and quickly layered onto degreased microscope slides previously dipped in $1 \%$ normal melting agarose (NMA) for the first layer. The agarose was allowed to set for $15 \mathrm{~min}$ at $4{ }^{\circ} \mathrm{C}$ before the addition of a final $90 \mu \mathrm{L}$ layer of low melting agarose (LMA). Cell lysis was carried out at $4{ }^{\circ} \mathrm{C}$ overnight by incubating the slides in lysis buffer $(2.5 \mathrm{M} \mathrm{NaCl}, 100 \mathrm{mM}$ Na2EDTA, $8 \mathrm{mM}$ Tris-HCl, $1 \%$ Triton $\mathrm{X}-100$ and $10 \% \mathrm{DMSO}, \mathrm{pH}=10)$. At the end of the lysis period slides were placed horizontally a black electrophoretic chamber and quickly submerged with electrophoretic alkaline buffer, $\mathrm{pH}>13\left(1 \mathrm{mM} \mathrm{Na} 2 \mathrm{EDTA}, 300 \mathrm{mM} \mathrm{NaOH}, 0{ }^{\circ} \mathrm{C}\right)$ and incubated for $20 \mathrm{~min}$ at $4^{\circ} \mathrm{C}$ to allow unwinding of DNA. The electrophoretic migration was performed for $20 \mathrm{~min}$ at $0.78 \mathrm{~V} \mathrm{~cm}^{-1}$ and $300 \mathrm{~mA}$. After electrophoresis, each slide was neutralized with $2 \mathrm{~mL}$ of neutralization buffer $(0.4 \mathrm{M}$ Tris- $\mathrm{HCl}, \mathrm{pH} 7.5)$, fixed in ethanol at $20^{\circ} \mathrm{C}$ and left to dry for at least $4 \mathrm{~h}$. DNA was stained with $75 \mu \mathrm{L}$ SYBR ${ }^{\text {TM }}$ Gold Nucleic Acid Gel Stain before the examination at 200× magnification under a Leica DMLS fluorescence microscope (Leica Microsystems GmbH, Wetzlar, Germany) (excitation filter BP 515-560 nm, barrier filter LP $580 \mathrm{~nm}$ ), using an automatic image analysis system (Comet Assay IV-Perceptive Instruments Ltd, Stone, Staffordshire, UK). In order to assess if the location of DNA-strand breaks caused by $\mathbf{1 -}\left(\boldsymbol{S}, \boldsymbol{R}_{\boldsymbol{p}}\right)$ treatment coincided with EdU incorporation sites after treatment cells were pulse-labelled with EdU $10 \mu \mathrm{M}$ before been harvested. Slides for the comet assay were prepared as usual and then labelled with AlexaFluor488 picolyl azide after the final dehydration prior to staining with SYBR Gold.

\section{CellTrace analysis}

Cellular proliferation was quantified by quantifying the time-dependent decrease in CellTrace Far Red fluorescence labelling as the result of cell division using a CellTrace cell proliferation kit (ThermoFisher Scientific, USA, Cat. No. C34564) according to manufacturer's instructions. Briefly, cells were pulse labelled with CellTrace Far Red (10 $\mu \mathrm{M}, 30$ minutes $)$ before treatment with $\mathbf{1 -}\left(\boldsymbol{S}, \boldsymbol{R}_{\boldsymbol{p}}\right)(0-5 \mu \mathrm{M})$ for 72 hours. At the end of the 
experiment cells were suspended by trypsinisation and fluorescence analysed by flow cytometry (BD FACSCalibur, BD Biosciences, USA).

\section{EdU labelling}

Nucleotide incorporation rate was assessed trough the Click-iT ${ }^{\mathrm{TM}}$ Plus EdU Alexa Fluor ${ }^{\mathrm{TM}}$ 488 Flow Cytometry Assay Kit (Thermo Scientific, Waltham, MA, US) according to manufacturer's specification. Briefly, ethynil-deoxy uridine incorporation was detected through click-labelling with Alexafluor488 picolyl azide and measured through both a BD FACSCalibur ${ }^{\mathrm{TM}}$ flow cytometer (Becton Dickinson, Franklin Lakes, NJ, US) equipped with a $488 \mathrm{~nm}$ argon laser and a $635 \mathrm{~nm}$ red diode laser and through a Nikon A1R Inverted Confocal/TIRF microscope (Nikon, Minato, Tokyo, Japan). DNA content in the cell population was counterstained with eBioscience ${ }^{\mathrm{TM}}$ 7-AAD Viability Staining Solution (Thermo Scientific, Waltham, MA, US) according to manufacturer's specifications. Single dye stained samples were run prior to the analysis to ensure no signal compensation was necessary. Flow cytometry samples were analysed in triplicate technical replicate and every experiment was repeated three times.

\section{Cell cycle analysis}

After treatment with different concentrations of $\mathbf{1}-\left(\boldsymbol{S}, \boldsymbol{R}_{\boldsymbol{p}}\right)$, cells were harvested, fixed and permeabilised as described previously (64). After centrifugation, cells were resuspended in PBS followed by incubation with propidium iodide $(0.01 \mathrm{mg} / \mathrm{mL})$ and RNAse A $(1 \mathrm{mg} / \mathrm{mL})$ (Qiagen, Germany,Cat. no. 19101) for $30 \mathrm{~min}$. The samples were analysed by flow cytometry using BD FACSCalibur (BD Biosciences, USA) in triplicate technical replicate and every experiment was repeated three times.

\section{DNA-fibre fluorography analysis}

MIAPaCa 2 cells were seeded at a density of $3 \times 10^{5}$ cells $/ \mathrm{mL}$ and incubated in $5 \% \mathrm{CO}_{2}, 37^{\circ} \mathrm{C}$ overnight. Cells were treated with $\mathbf{1 -}\left(\boldsymbol{S}, \boldsymbol{R}_{\boldsymbol{p}}\right)$ for $24 \mathrm{~h}$. Following treatment cells were pulselabelled with $25 \mu \mathrm{M}$ CldU for 20 min followed by second labelling with $250 \mu \mathrm{M}$ IdU for an additional $20 \mathrm{~min}$. Cells were harvested and the fibres were spread as described previously (65). DNA fibres were immunolabelled to detect IdU with mouse anti-BrdU (1:70; BectonDickinson) and CldU with rat anti-BrdU (1:200; Abcam) antibodies and incubated overnight at $4^{\circ} \mathrm{C}$. Following fixation in $4 \%$ paraformaldehyde, the slides were incubated with secondary antibodies goat anti-rat Alexafluor 555 (1:500; ThermoFisher Scientific) and goat anti-mouse Alexafluor 488 (1:500; ThermoFisher Scientific) for 90 min. The images were captured using confocal microscopy with an oil immersion objective and analysed using ImageJ. At least 1000 fibres per condition from three independent experiments were quantified by measuring the combined length $(\mu \mathrm{m})$ of the red and green fluorescent label. Fibre length in $\mu \mathrm{m}$ was then expressed as $\mathrm{kB}$ of DNA as described previously (27) where 1 $\mu \mathrm{m}$ is estimated to be $2.59 \mathrm{kB}$ of extended DNA.

\section{Gamma-H2AX staining}

MIA PaCa-2 cells were treated with $10 \mu \mathrm{M} \mathbf{1}-\left(\boldsymbol{S}, \boldsymbol{R}_{\boldsymbol{p}}\right)$ or positive control etoposide $5 \mu \mathrm{M}$ for $24 \mathrm{~h}$ for comparison. Negative controls were treated with $0.5 \%$ DMSO (Sigma, Ireland), vehicle solvent. After treatment, cells were detached using standard trypsin/EDTA protocol and cell pellets were obtained. Cells were fixed in ice-cold $70 \%$ ethanol and stored overnight at 4 C. Fixed cells were centrifuged and resuspended in 0.25\% Triton X-100 (Sigma, Ireland) (Cat. no. T8787) for $10 \mathrm{~min}$. After centrifugation, cells were resuspended in blocking solution ( $2 \%$ BSA) for 30 min at RT. Blocking solution was removed by centrifugation and exposed to the anti-gamma H2AX (phospho S139) antibody (1:500) (Abcam, UK) (Cat. no. ab26350) 
in blocking solution for $1 \mathrm{~h}$ at RT. The primary antibody was removed, cells were washed and incubated with the goat anti-mouse (FITC) antibody (1:200) (ThermoFisher Scientific, USA) (Cat. no. 62-6511) in blocking solution for $1 \mathrm{~h}$ in the dark at room temperature. After removing the secondary antibody and washing, the cell pellets were resuspended in $1 \mathrm{~mL}$ blocking solution. The samples were analysed by flow cytometry using BD FACSCalibur (BD Biosciences, USA) in triplicate technical replicate and every experiment was repeated three times.

For confocal analysis, cells were fixed in 4\% paraformaldehyde on a rocker for $10 \mathrm{~min}$ at RT followed by incubation with $0.1 \%$ Triton X-100 (Sigma, Ireland) for $10 \mathrm{~min}$. After washing with PBST, cells were blocked wit 2\% BSA in PBST for $1 \mathrm{~h}$ at RT. Cells were washed and incubated with anti-gamma H2AX (phospho S139) antibody (1:500) (Abcam, UK) (Cat. no. ab26350) overnight at $4^{\circ} \mathrm{C}$ in a humidified chamber. Cells were washed and incubated with goat anti-mouse (FITC) antibody (1:200) (ThermoFisher Scientific, USA) (Cat. no. 62-6511) for $1 \mathrm{~h}$ in the dark at RT. After PBST wash, cells were incubated with propidium iodide $(0.01$ $\mathrm{mg} / \mathrm{mL}$ ) for $10 \mathrm{~min}$. Samples were washed again and coverslips (ThermoFisher Scientific, USA) were applied using hydromount mounting media. The slides were allowed to dry for $1 \mathrm{~h}$ in the dark at RT. The slides were read using Nikon A1R Inverted Confocal/TIRF microscope (Nikon, Minato, Tokyo, Japan) using a x100 oil-immersion objective.

\section{Acknowledgements}

We thank the University of Birmingham for financial support in the award of a $\mathrm{PhD}$ studentship to MR and the EPSRC (Follow-on-fund) and MRC (Confidence in Concept) for funding for ZK. and AP respectively. MKI acknowledges the Ministry of Higher Education $\&$ Scientific Research in Iraq and The University of Kirkuk for funding and support. The Centre for Chemical and Materials Analysis at the University of Birmingham is acknowledged for technical support.

\section{References}

1. C. Allemani et al., Global surveillance of trends in cancer survival 2000-14 (CONCORD-3): analysis of individual records for 37513025 patients diagnosed with one of 18 cancers from 322 population-based registries in 71 countries. Lancet 391, 1023-1075 (2018).

2. T. Conroy et al., FOLFIRINOX versus Gemcitabine for Metastatic Pancreatic Cancer. New Engl. J. Med. 364, 1817-1825 (2011).

3. V. Pacheco-Barcia et al., Gemcitabine plus nab-paclitaxel versus modified FOLFIRINOX as first line chemotherapy in metastatic pancreatic cancer: A comparison of toxicity and survival. Ann. Oncol. 29 Suppl 5, v46 (2018).

4. N. Williet et al., Folfirinox versus gemcitabine/nab-paclitaxel as first-line therapy in patients with metastatic pancreatic cancer: a comparative propensity score study. Therap Adv Gastroenterol 12, 1756284819878660 (2019).

5. I. Cho et al., FOLFIRINOX versus gemcitabine plus nab-paclitaxel for treatment of metastatic pancreatic cancer: a single-center cohort study. Ann. Oncol. 29 Suppl 5, v45 (2018).

6. R. Ramesh, D. S. Reddy, Quest for Novel Chemical Entities through Incorporation of Silicon in Drug Scaffolds. J. Med. Chem. 61, 3779-3798 (2018). 
7. J. Karges, R. W. Stokes, S. M. Cohen, Metal complexes for therapeutic applications. Trends in Chemistry (2021).

8. G. Jaouen, A. Vessieres, S. Top, Ferrocifen type anti cancer drugs. Chem Soc Rev 44, 8802-8817 (2015).

9. M. Patra, G. Gasser, The medicinal chemistry of ferrocene and its derivatives. Nature Reviews Chemistry 1, 0066 (2017).

10. G. Gasser, N. Metzler-Nolte, The potential of organometallic complexes in medicinal chemistry. Curr. Opin. Chem. Biol. 16, 84-91 (2012).

11. P. Kopfmaier, H. Kopf, E. W. Neuse, Ferrocenium Salts - the 1st Antineoplastic Iron Compounds. Angew Chem Int Edit 23, 456-457 (1984).

12. M. Patra et al., Ferrocenyl Derivatives of the Anthelmintic Praziquantel: Design, Synthesis, and Biological Evaluation. J. Med. Chem. 55, 8790-8798 (2012).

13. Z. H. Chohan, Synthesis of organometallic-based biologically active compounds: In vitro antibacterial, antifungal and cytotoxic properties of some sulfonamide incorporated ferrocences. J. Enzyme Inhib. Med. Chem. 24, 169-175 (2009).

14. R. Rubbiani, O. Blacque, G. Gasser, Sedaxicenes: potential new antifungal ferrocenebased agents? Dalton Trans 45, 6619-6626 (2016).

15. W. A. Wani, E. Jameel, U. Baig, S. Mumtazuddin, L. T. Hun, Ferroquine and its derivatives: new generation of antimalarial agents. Eur J Med Chem 101, 534-551 (2015).

16. S. Top et al., Synthesis, biochemical properties and molecular modelling studies of organometallic specific estrogen receptor modulators (SERMs), the ferrocifens and hydroxyferrocifens: evidence for an antiproliferative effect of hydroxyferrocifens on both hormone-dependent and hormone-independent breast cancer cell lines. Chemistry 9, 5223-5236 (2003).

17. C. Bruyere et al., Ferrocifen derivatives that induce senescence in cancer cells: selected examples. J Inorg Biochem 141, 144-151 (2014).

18. J. A. Carmona-Negron, A. Santana, A. L. Rheingold, E. Melendez, Synthesis, structure, docking and cytotoxic studies of ferrocene-hormone conjugates for hormone-dependent breast cancer application. Dalton Trans 48, 5952-5964 (2019).

19. G. Romeo, U. Chiacchio, A. Corsaro, P. Merino, Chemical synthesis of heterocyclicsugar nucleoside analogues. Chem Rev 110, 3337-3370 (2010).

20. H. V. Nguyen et al., Organometallic nucleoside analogues with ferrocenyl linker groups: synthesis and cancer cell line studies. J. Med. Chem. 57, 5817-5822 (2014).

21. J. L. Kedge et al., Organometallic Nucleoside Analogues: Effect of Hydroxyalkyl Linker Length on Cancer Cell Line Toxicity. European Journal of Inorganic Chemistry 10.1002/ejic.201600853, 466-476 (2017).

22. H. A. Burris, 3rd et al., Improvements in survival and clinical benefit with gemcitabine as first-line therapy for patients with advanced pancreas cancer: a randomized trial. J Clin Oncol 15, 2403-2413 (1997).

23. M. Galanski, Recent developments in the field of anticancer platinum complexes. Recent Pat Anticancer Drug Discov 1, 285-295 (2006).

24. D. Szklarczyk et al., STRING v10: protein-protein interaction networks, integrated over the tree of life. Nucleic Acids Res. 43, D447-452 (2015).

25. B. Ewald, D. Sampath, W. Plunkett, H2AX phosphorylation marks gemcitabineinduced stalled replication forks and their collapse upon S-phase checkpoint abrogation. Mol. Cancer Ther. 6, 1239-1248 (2007).

26. D. Sampath, V. A. Rao, W. Plunkett, Mechanisms of apoptosis induction by nucleoside analogs. Oncogene 22, 9063-9074 (2003). 
27. J. Nieminuszczy, R. A. Schwab, W. Niedzwiedz, The DNA fibre technique - tracking helicases at work. Methods 108, 92-98 (2016).

28. M. Ismail et al., Effect of regiochemistry and methylation on the anticancer activity of a ferrocene-containing organometallic nucleoside analogue. ChemBioChem 10.1002/cbic.202000124 (2020).

29. M. Wenzel, Y. Wu, E. Liss, E. W. Neuse, [Stability of ferricinium cations and their cytostatic effect]. Z Naturforsch C J Biosci 43, 963-966 (1988).

30. P. Kopf-Maier, H. Kopf, E. W. Neuse, Ferricenium complexes: a new type of watersoluble antitumor agent. J. Cancer Res. Clin. Oncol. 108, 336-340 (1984).

31. C. Lu et al., Quantitative analyses of ROS and RNS production in breast cancer cell lines incubated with ferrocifens. ChemMedChem 9, 1286-1293 (2014).

32. A. Vessieres et al., A ferrocenyl derivative of hydroxytamoxifen elicits an estrogen receptor-independent mechanism of action in breast cancer cell lines. $J$ Inorg Biochem 104, 503-511 (2010).

33. H. Hagen et al., Aminoferrocene-based prodrugs activated by reactive oxygen species. J. Med. Chem. 55, 924-934 (2012).

34. M. K. Ismail et al., Organometallic nucleoside analogues: effect of the metallocene metal atom on cancer cell line toxicity. Dalton Trans 49, 1181-1190 (2020).

35. J. K. Barton, R. M. B. Silva, E. O'Brien, Redox Chemistry in the Genome: Emergence of the $[4 \mathrm{Fe} 4 \mathrm{~S}]$ Cofactor in Repair and Replication. Annu. Rev. Biochem. 88, 163-190 (2019).

36. A. G. Baranovskiy, H. M. Siebler, Y. I. Pavlov, T. H. Tahirov, Iron-Sulfur Clusters in DNA Polymerases and Primases of Eukaryotes. Methods Enzymol. 599, 1-20 (2018).

37. L. Huang et al., Low-dose 5-fluorouracil induces cell cycle G2 arrest and apoptosis in keloid fibroblasts. Br. J. Dermatol. 163, 1181-1185 (2010).

38. P. Cappella et al., Cell cycle effects of gemcitabine. Int. J. Cancer 93, 401-408 (2001).

39. E. R. Parrilla-Castellar, S. J. Arlander, L. Karnitz, Dial 9-1-1 for DNA damage: the Rad9-Hus1-Rad1 (9-1-1) clamp complex. DNA Repair (Amst) 3, 1009-1014 (2004).

40. L. M. Karnitz et al., Gemcitabine-induced activation of checkpoint signaling pathways that affect tumor cell survival. Mol. Pharmacol. 68, 1636-1644 (2005).

41. J. Fredebohm, J. Wolf, J. D. Hoheisel, M. Boettcher, Depletion of RAD17 sensitizes pancreatic cancer cells to gemcitabine. J. Cell Sci. 126, 3380-3389 (2013).

42. B. J. Lamarche, N. I. Orazio, M. D. Weitzman, The MRN complex in double-strand break repair and telomere maintenance. FEBS Lett. 584, 3682-3695 (2010).

43. B. Ewald, D. Sampath, W. Plunkett, ATM and the Mre11-Rad50-Nbs1 complex respond to nucleoside analogue-induced stalled replication forks and contribute to drug resistance. Cancer Res. 68, 7947-7955 (2008).

44. B. Ewald, D. Sampath, W. Plunkett, Nucleoside analogs: molecular mechanisms signaling cell death. Oncogene 27, 6522-6537 (2008).

45. B. M. Sirbu et al., Analysis of protein dynamics at active, stalled, and collapsed replication forks. Genes Dev. 25, 1320-1327 (2011).

46. J. Bartek, J. Lukas, Chk1 and Chk2 kinases in checkpoint control and cancer. Cancer Cell 3, 421-429 (2003).

47. M. Liang, T. Zhao, L. Ma, Y. Guo, CHK1 inhibition sensitizes pancreatic cancer cells to gemcitabine via promoting CDK-dependent DNA damage and ribonucleotide reductase downregulation. Oncol. Rep. 39, 1322-1330 (2018).

48. D. Barnard et al., LY2603618, a selective CHK1 inhibitor, enhances the anti-tumor effect of gemcitabine in xenograft tumor models. Invest New Drugs 34, 49-60 (2016). 
49. S. B. Koh et al., CHK1 Inhibition Synergizes with Gemcitabine Initially by Destabilizing the DNA Replication Apparatus. Cancer Res. 75, 3583-3595 (2015).

50. R. Montano et al., Sensitization of human cancer cells to gemcitabine by the Chk1 inhibitor MK-8776: cell cycle perturbation and impact of administration schedule in vitro and in vivo. BMC Cancer 13, 604 (2013).

51. V. A. Venkatesha et al., Sensitization of pancreatic cancer stem cells to gemcitabine by Chk1 inhibition. Neoplasia 14, 519-525 (2012).

52. E. Calvo et al., Phase I Study of CHK1 Inhibitor LY2603618 in Combination with Gemcitabine in Patients with Solid Tumors. Oncology-Basel 91, 251-260 (2016).

53. J. Liu et al., Down-regulation of GADD45A enhances chemosensitivity in melanoma. Sci Rep 8, 4111 (2018).

54. H. H. Wang, T. Y. Chang, W. C. Lin, K. C. Wei, J. W. Shin, GADD45A plays a protective role against temozolomide treatment in glioblastoma cells. Sci Rep 7, 8814 (2017).

55. M. B. Kastan et al., A mammalian cell cycle checkpoint pathway utilizing p53 and GADD45 is defective in ataxia-telangiectasia. Cell 71, 587-597 (1992).

56. S. Jin et al., Transcription factors Oct-1 and NF-YA regulate the p53-independent induction of the GADD45 following DNA damage. Oncogene 20, 2683-2690 (2001).

57. J. Hildesheim, A. J. Fornace, Jr., Gadd45a: an elusive yet attractive candidate gene in pancreatic cancer. Clin. Cancer. Res. 8, 2475-2479 (2002).

58. T. Ozaki et al., Impact of RUNX2 on drug-resistant human pancreatic cancer cells with p53 mutations. BMC Cancer 18, 309 (2018).

59. P. Acedo, A. Fernandes, J. Zawacka-Pankau, Activation of TAp73 and inhibition of TrxR by Verteporfin for improved cancer therapy in TP53 mutant pancreatic tumors. Future Sci OA 5, FSO366 (2019).

60. M. Nakamura et al., Improvement of gemcitabine sensitivity of p53-mutated pancreatic cancer MiaPaCa-2 cells by RUNX2 depletion-mediated augmentation of TAp73-dependent cell death. Oncogenesis 5, e233 (2016).

61. M. Sang et al., Impact of RUNX2 gene silencing on the gemcitabine sensitivity of p53mutated pancreatic cancer MiaPaCa2 spheres. Oncol. Rep. 39, 2749-2758 (2018).

62. S. Kato et al., Understanding the function-structure and function-mutation relationships of p53 tumor suppressor protein by high-resolution missense mutation analysis. Proc Natl Acad Sci U S A 100, 8424-8429 (2003).

63. J. C. Stockert, R. W. Horobin, L. L. Colombo, A. Blazquez-Castro, Tetrazolium salts and formazan products in Cell Biology: Viability assessment, fluorescence imaging, and labeling perspectives. Acta Histochem 120, 159-167 (2018).

64. K. H. Kim, J. M. Sederstrom, Assaying Cell Cycle Status Using Flow Cytometry. Curr Protoc Mol Biol 111, 2826 21-28 2611 (2015).

65. J. Henry-Mowatt et al., XRCC3 and Rad51 modulate replication fork progression on damaged vertebrate chromosomes. Mol. Cell 11, 1109-1117 (2003). 
<smiles>Cc1cn(CCc2cc(F)cc([C@H](C)CCO)c2)c(=O)[nH]c1=O</smiles>

B)

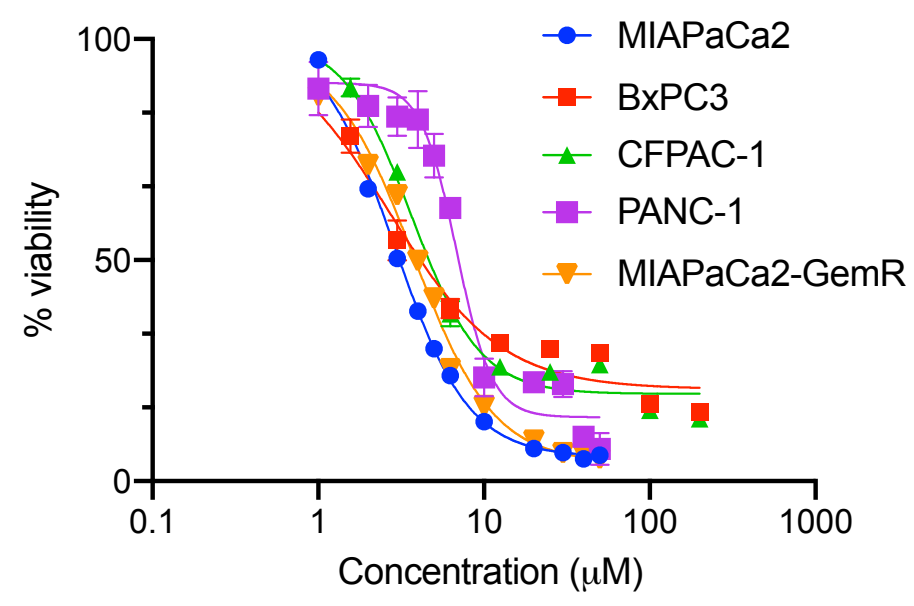

C)

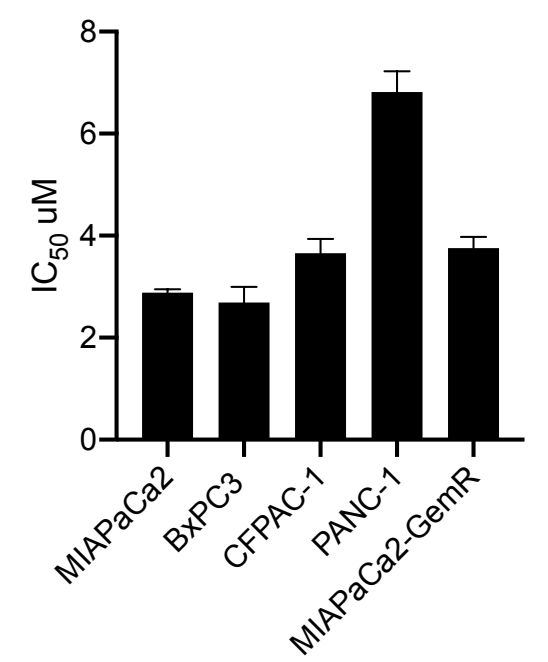

D)

\begin{tabular}{|l|l|l|l|l|l|}
\hline & MIAPaCa2 & $\begin{array}{l}\text { MIAPaCa2- } \\
\text { GemR }\end{array}$ & BxPC3 & CFPAC-1 & PANC-1 \\
\hline $\begin{array}{l}\text { 1-(S,Rp) } \\
(\mu M)\end{array}$ & $2.9(2.7-3.0)$ & $3.7(4.2-4.3)$ & $\begin{array}{l}2.7(2.1- \\
3.4)\end{array}$ & $3.7(3.1-4.2)$ & $\begin{array}{l}6.8(6.0- \\
7.7)\end{array}$ \\
\hline $\begin{array}{l}\text { Cisplatin } \\
(\mu M)\end{array}$ & $4.6(4.2-5.0)$ & $1.2(1.0-1.3)$ & $\begin{array}{l}1.0(0.9- \\
1.1)\end{array}$ & $4.9(3.1-7.9)$ & $\begin{array}{l}4.5(3.7- \\
6.0)\end{array}$ \\
\hline $\begin{array}{l}\text { Gemcitabine } \\
(n M)\end{array}$ & $6.0(5.7-6.4)$ & $>500$ & $\begin{array}{l}16.0(13.6- \\
18.7)\end{array}$ & $5.5(4.2-7.3)$ & $\begin{array}{l}17.4(15.4- \\
19.6)\end{array}$ \\
\hline
\end{tabular}

Figure 1:1-(S, $\left.\boldsymbol{R}_{\boldsymbol{p}}\right)$ whose chemical structure is shown in A) with ferrocene high-lighted in red is cytotoxic to a panel on pancreatic ductal adenoma carcinoma cells. B) Cytotoxicity curves in pancreatic ductal adenoma carcinoma (PDAC) cell lines treated with $\mathbf{1 -}\left(\boldsymbol{S}, \boldsymbol{R}_{\boldsymbol{p}}\right)$ for 72 hours as assessed by the MTT assay. The results represent the mean of three independent biological experiments $(\mathrm{n}=3)$. C) Modelled $\mathrm{IC}_{50}( \pm \mathrm{SD})$ values of 1-

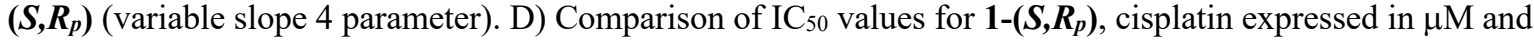
gemcitabine expressed in $\mathrm{nM}$ in the panel of 5 pancreatic ductal adenoma cells. The values in parentheses are the $95 \%$ CIs. The results represent the mean from three independent biological experiments $(n=3)$. 
A
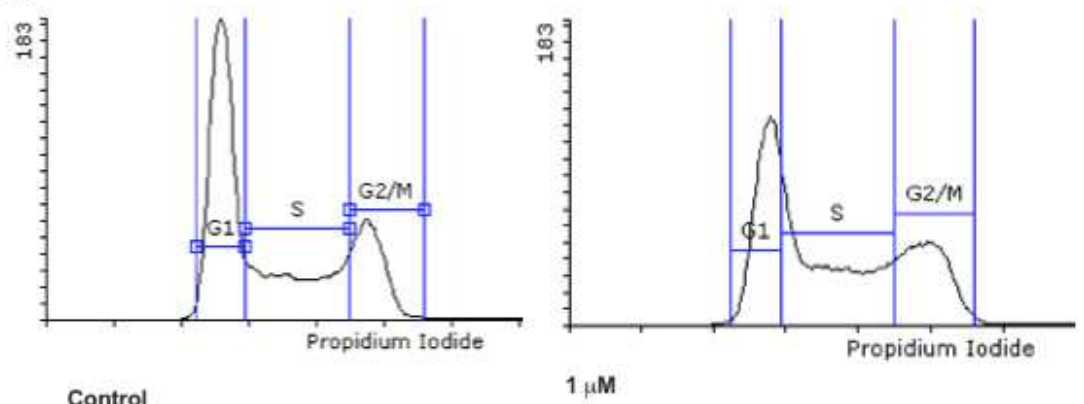

Control
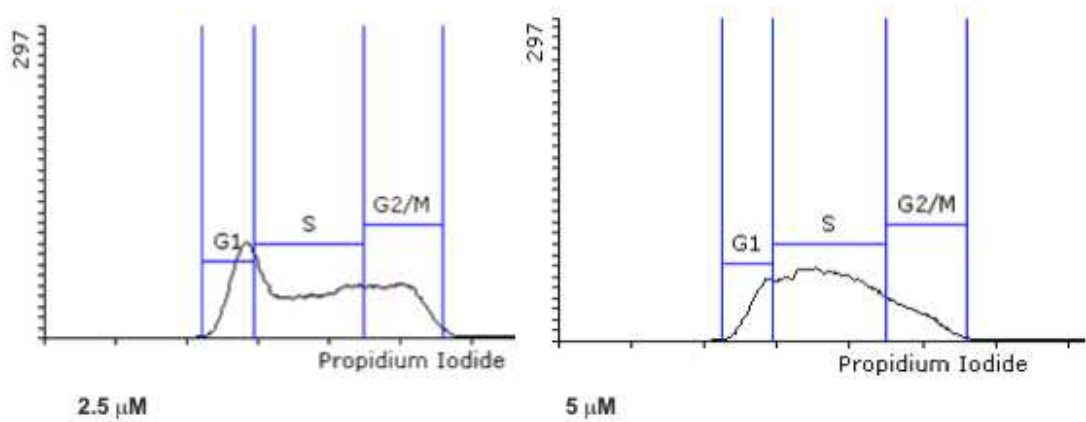

B

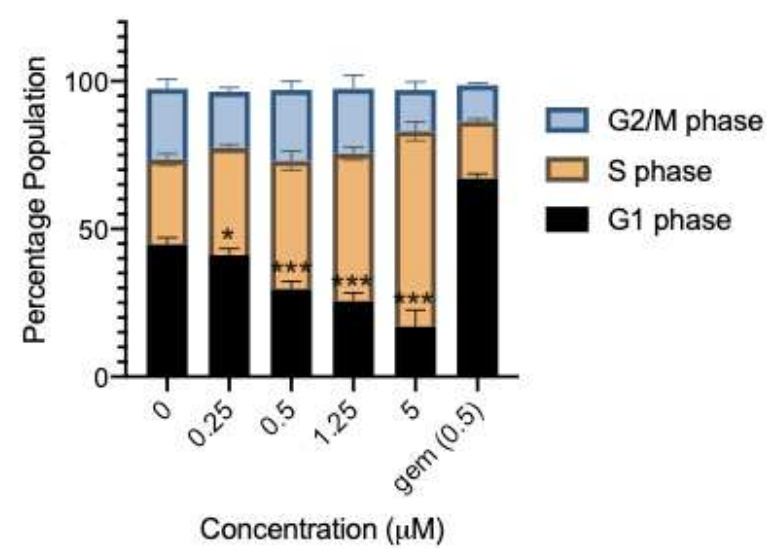

Figure 2: 1-(S, $\left.\boldsymbol{R}_{\boldsymbol{p}}\right)$ causes concentration dependent S-phase arrest in MIAPaCa2 pancreatic ductal adenoma carcinoma cells. Cells were treated with $\mathbf{1}-\left(\boldsymbol{S}, \boldsymbol{R}_{\boldsymbol{p}}\right)(0-5 \mu \mathrm{M})$ for 24 hours before staining with propidium iodide and analysis by flow cytometry. A) Representative histograms from cells treated with $0,1,2.5$ and $5 \mu \mathrm{M}$ 1$\left(\boldsymbol{S}, \boldsymbol{R}_{\boldsymbol{p}}\right)$. B) Graphical representation of data, the results represent the mean of three independent biological experiments $(( \pm \mathrm{SD}, \mathrm{n}=3) . * * *$ and $* * *$ statistically significantly different as assessed by 2 -way ANOVA followed by Dunnett's multiple comparison t-test. As a positive control cells were also treated with $0.5 \mu \mathrm{M}$ gemcitabine. 
A

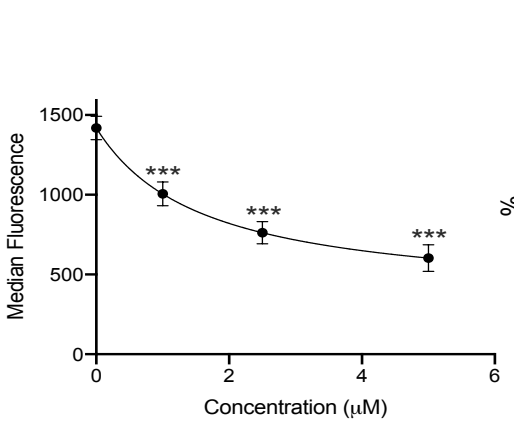

C

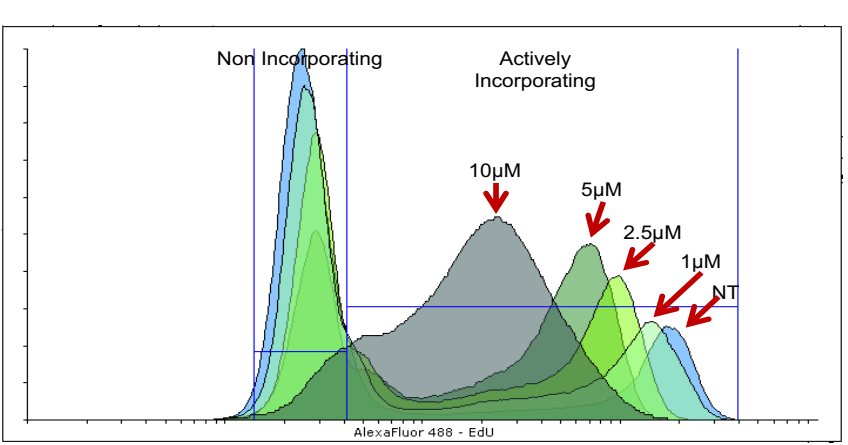

D
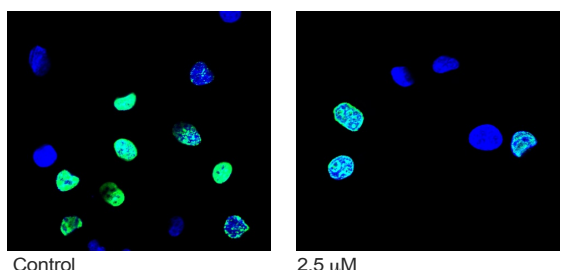

$2.5 \mu \mathrm{M}$
B $\square$ Incorporating

Don-incorporating

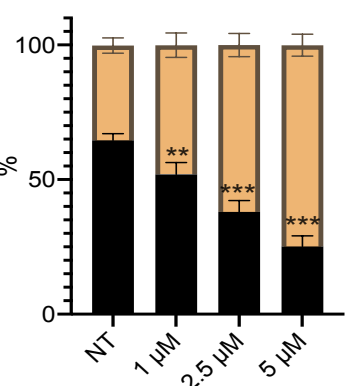

$\mathrm{F}$
$\mathrm{E}$
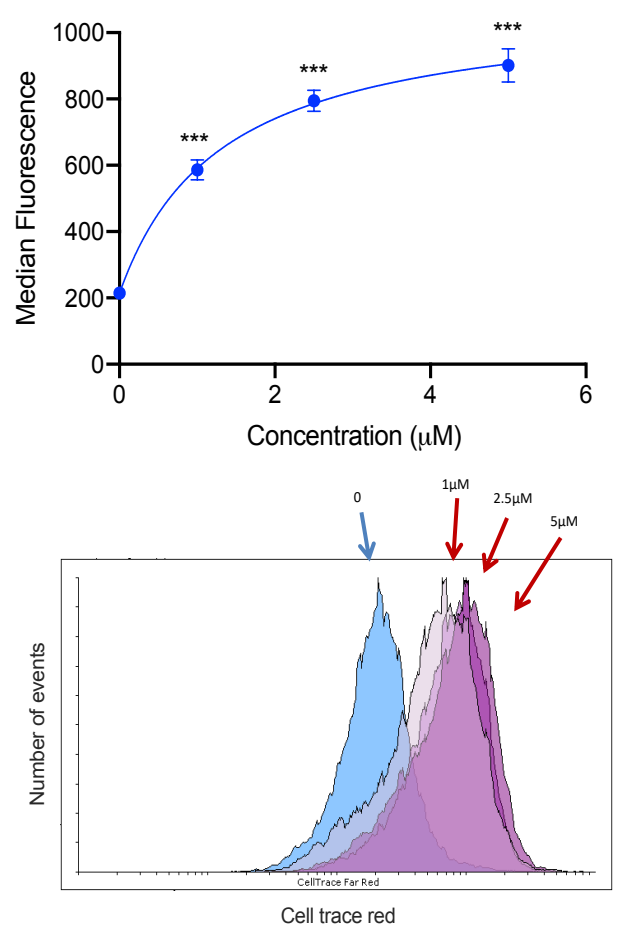

Figure 3: 1-( $\left.\boldsymbol{S}, \boldsymbol{R}_{p}\right)$ inhibits replication of genomic DNA in MIAPaCa2 pancreatic ductal adenoma carcinoma cells. A) Incorporation of EdU into replicating DNA as assessed by flow cytometry following treatment of cells with 1-(S, $\left.\boldsymbol{R}_{p}\right)$ for 24 hours. *** Significantly different from untreated control (1-way ANOVA followed by a post-hoc Dunnett's t-test). B) Percentage of EdU incorporating and non-incorporating cells following treatment with 1-(S, $\left.\boldsymbol{R}_{\boldsymbol{p}}\right)(24 \mathrm{~h})$ as quantified using the criteria outlined in C) for a representative experiment. D) Confocal microscopy confirms reduced EdU incorporation (green fluorescence) into genomic DNA in the nuclei of cells counter-stained with DAPI (blue fluorescence). E) Median cellular labelling with CellTrace Far Red. F)

Representative histograms from an individual experiment. The results represent the mean of three independent biological experiments $( \pm \mathrm{SD}, \mathrm{n}=3)$. $* * *$ Statistically significant from control $\{\mathrm{P}<0.001,1$-way ANOVA followed by a post-hoc Dunnett's t-test). The calculated $\mathrm{EC}_{50}$ of $\mathbf{1}-\left(\boldsymbol{S}, \boldsymbol{R}_{p}\right)$ was $1.3 \mu \mathrm{M}(95 \% \mathrm{CI}$ 0.9-1.9 $\mu \mathrm{M})$. 

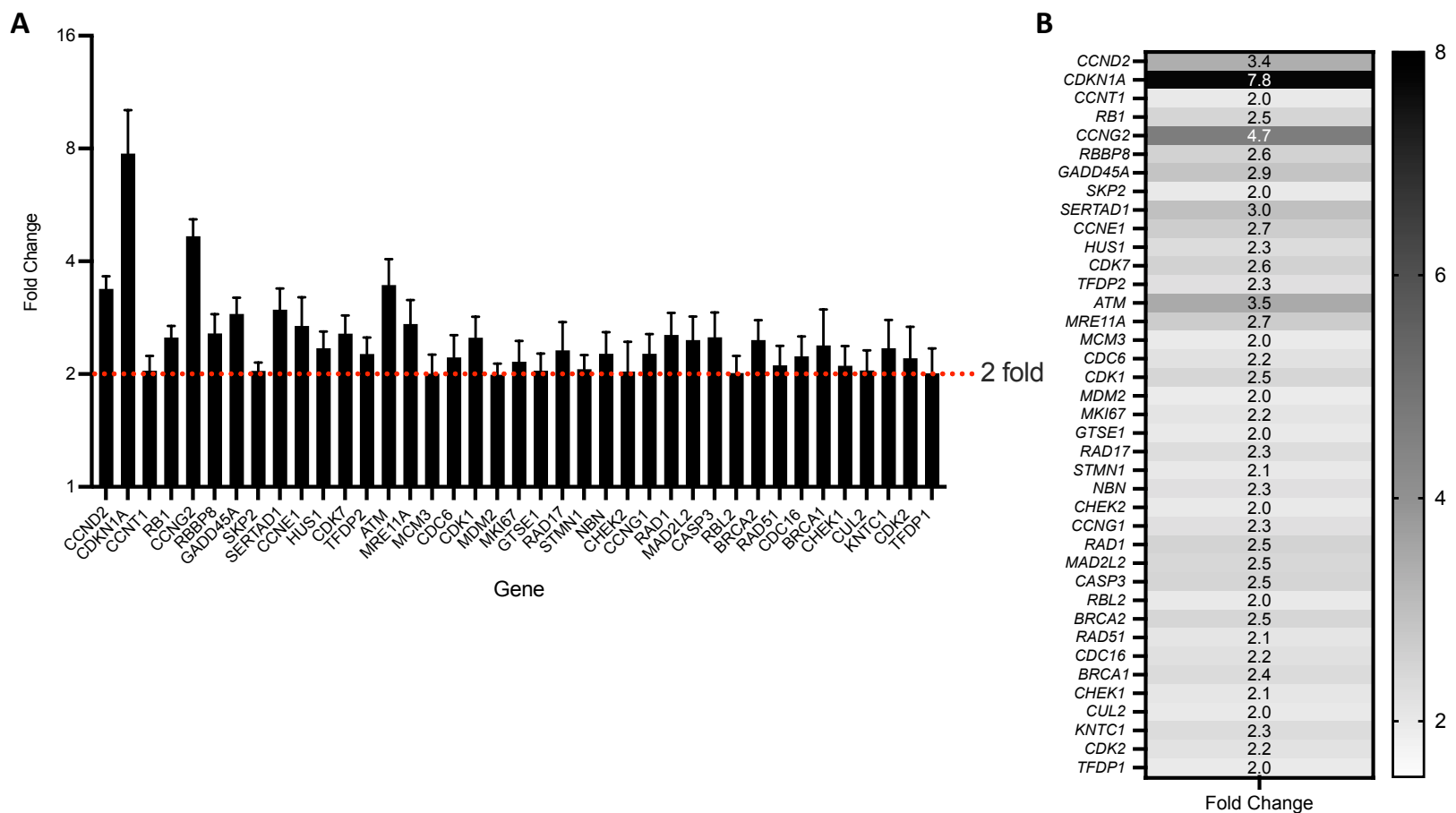

Figure 4: List of 39 genes related to DNA-repair that are statistically significantly upregulated in MIAPaCa2 cells following treatment with $\mathbf{1 -}\left(\boldsymbol{S}, \boldsymbol{R}_{\boldsymbol{p}}\right)(10 \mu \mathrm{M}, 24$ hours $)$. A) Graphed as fold change $\left(2^{-\mathrm{ddCq}}\right)$ and B) as a heat map for clarity. The results represent the mean of three independent biological experiments $( \pm S D, n=3)$.

Statistically significantly changed genes plotted relative to $G A P D H$ as $2^{-\mathrm{dCq}}$ are shown in supplementary Figure .S3 

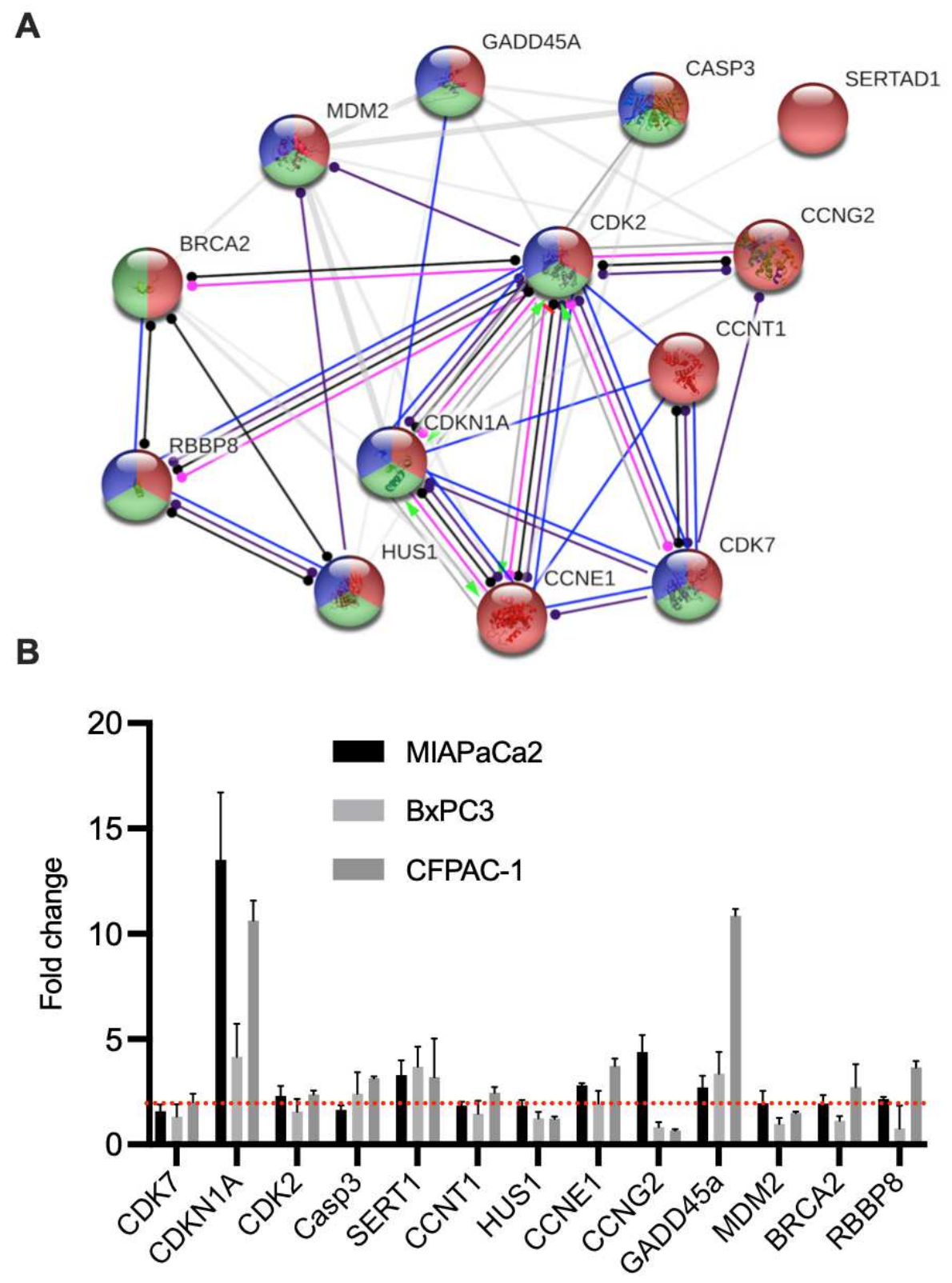

Figure 5: 1-(S, $\left.\boldsymbol{R}_{p}\right)$ induces a conserved transcriptional response in three PDAC cell lines. A) STRING network analysis (https://string-db.org) of the 13-genes transcriptional activated in MIAPaCa2 and at least one other PDAC cell line following treatment Within the network major GO-terms represented included: GO:0051726 regulation of cell cycle (coloured red), GO:0045786 negative regulation of cell cycle (coloured blue) and GO:0006974 cellular response to DNA damage stimulus (coloured green). Interconnecting lines within the

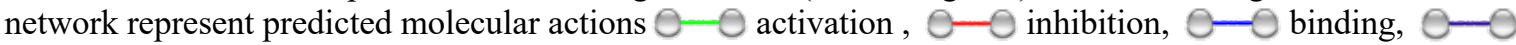

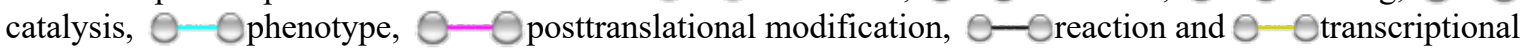
regulation. B) Quantification of fold-changes as assessed by qPCR in MIAPaCa2, BxPC3 and CFPAC-1 cells following treatment with $\mathbf{1}-\left(\boldsymbol{S}, \boldsymbol{R}_{p}\right)(10 \mu \mathrm{M}, 24$ hours $)$. The red dotted line represents 2-fold increase compared to untreated control. The results represent the mean of three independent biological experiments $( \pm S D, n=3)$. 

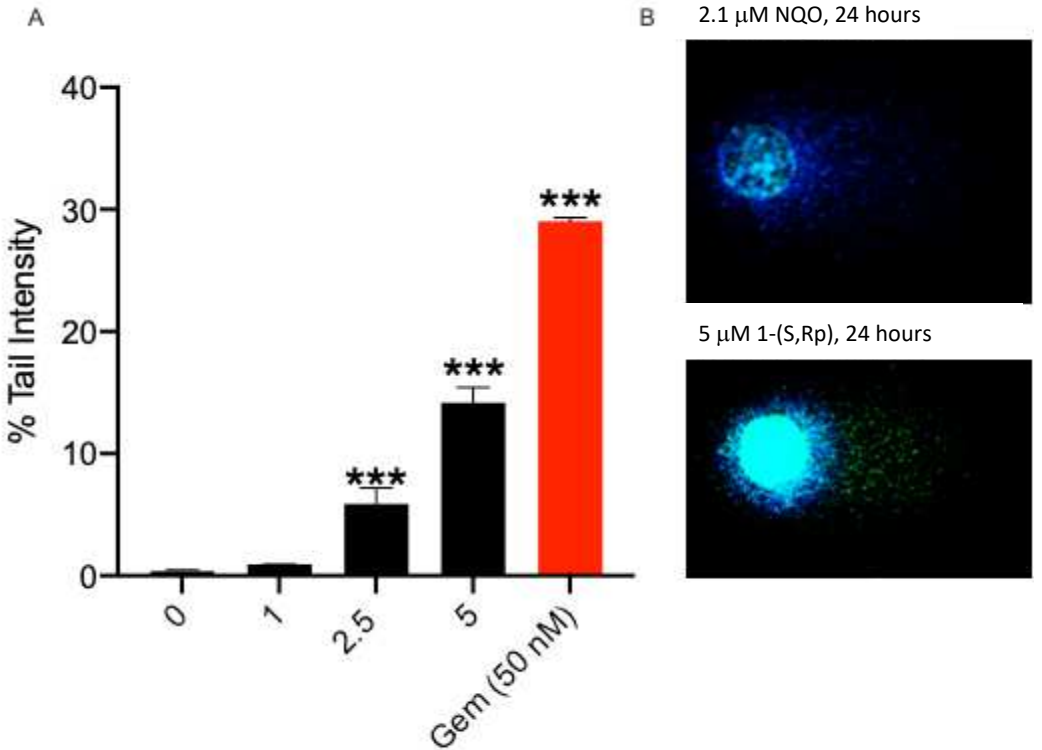

$5 \mu \mathrm{M}$ 1-(S,Rp), 24 hours

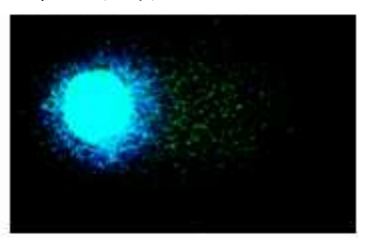

Figure 6: 1-(S, $\left.\boldsymbol{R}_{p}\right)$ induced DNA-single strand breaks in recently replicated genomic DNA. A) Concentrationdependent increase in single stranded DNA-breaks following treatment with $\mathbf{1}-\left(\boldsymbol{S}, \boldsymbol{R}_{p}\right)(0-5 \mu \mathrm{M}, 24$ hours $)$ as assessed by the comet assay. B) Pulse labelling with EdU (green fluorescence) prior to treatment confirms that DNA-strand breaks occur in recently replicated DNA following treatment with 1-(S, $\left.\boldsymbol{R}_{p}\right)(5 \mu \mathrm{M}, 24$ hours $)$ but not when treated with NQO a direct acting genotoxic chemical, where only non-EdU labelled DNA counterstained with Hoechst (blue fluorescence) is visible in the comet tail. The results represent the mean of three independent biological experiments $( \pm \mathrm{SD}, \mathrm{n}=3), * * *$ significantly different from untreated control $(\mathrm{P}<0.001,1$-way ANOVA followed by a post-hoc Dunnett's t-test). 
A

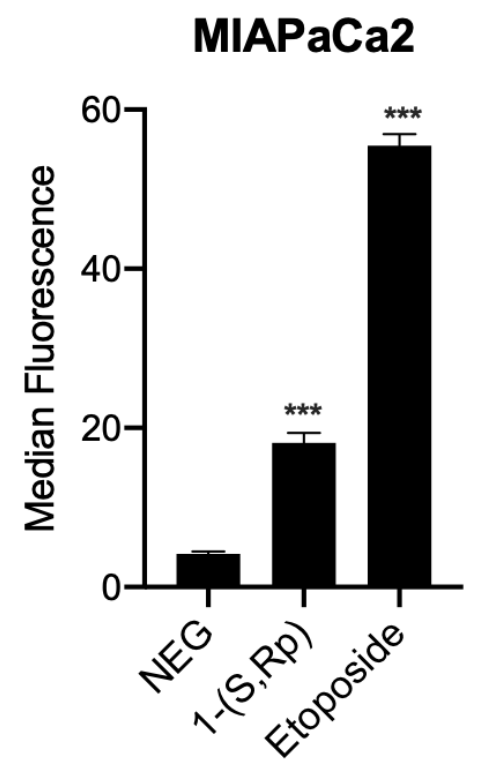

C

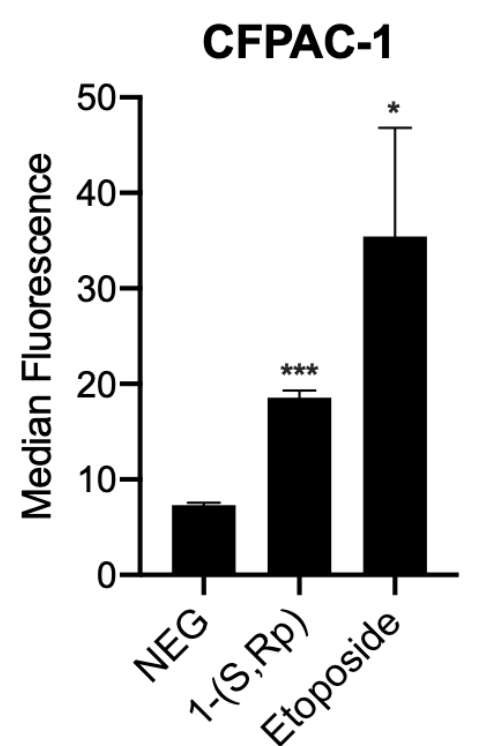

B
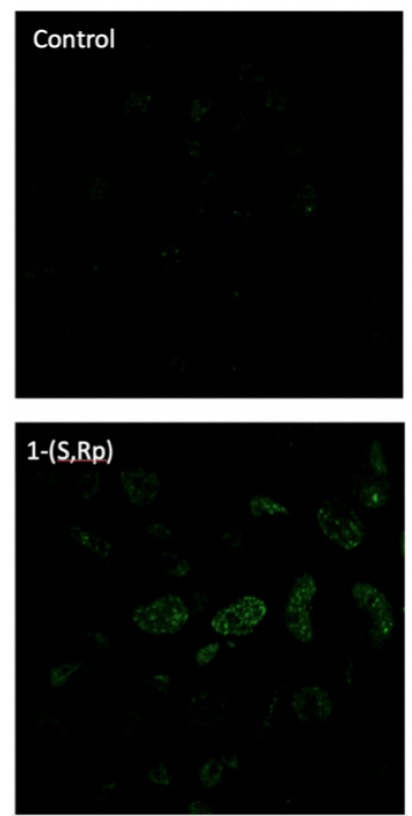

D

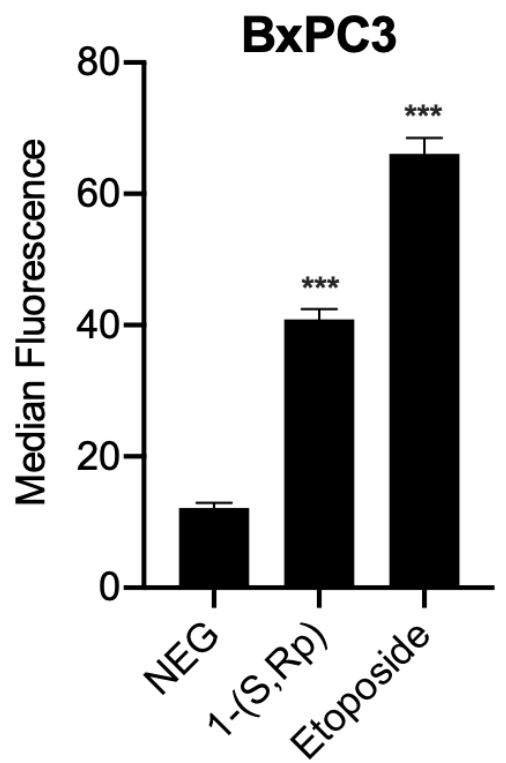

Figure 7: 1-(S, $\left.\boldsymbol{R}_{\boldsymbol{p}}\right)(10 \mu \mathrm{M}, 24$ hours $)$ - induces double-stranded DNA breaks as assessed by gamma-H2AX phosphorylation in pancreatic ductal adeno carcinoma cells. A) and B) MIAPaCa2 cells as assessed by flow cytometry and confocal microscopy respectively. C) CFPAC-1 and D) BxPC3 cells as assessed by flow cytometry. Etoposide ( $5 \mu \mathrm{M}, 24$ hours) was used as a positive control. The results represent the mean of three independent biological experiments $( \pm \mathrm{SD}, \mathrm{n}=3)$. * and *** Statistically significantly different from control, $\mathrm{P}<0.05$ and 0.001 respectively (1-way ANOVA followed by a post-hoc Dunnett's t-test). 
A)

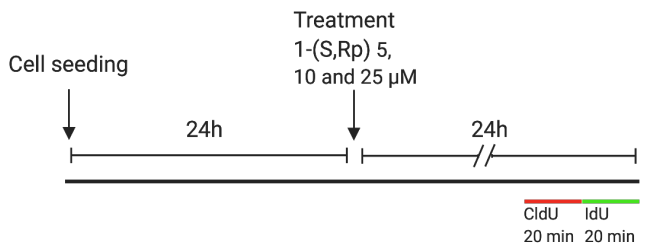

B)
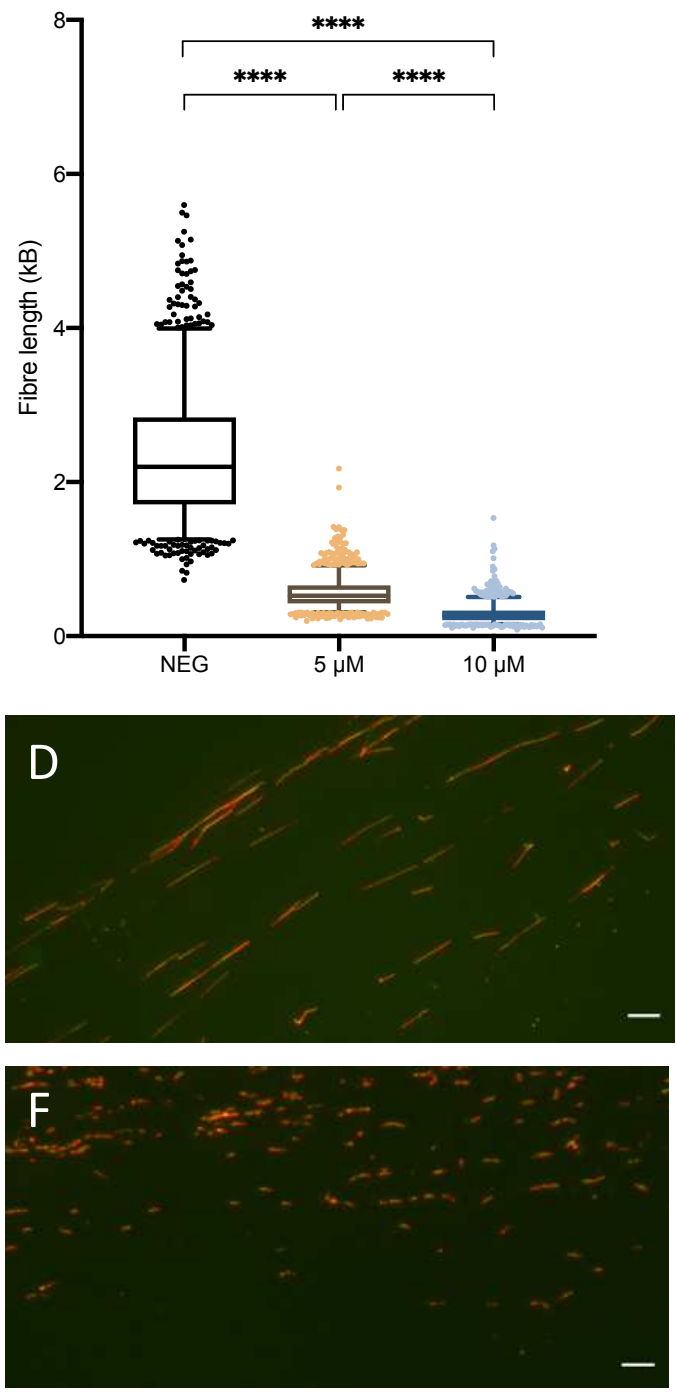

C)
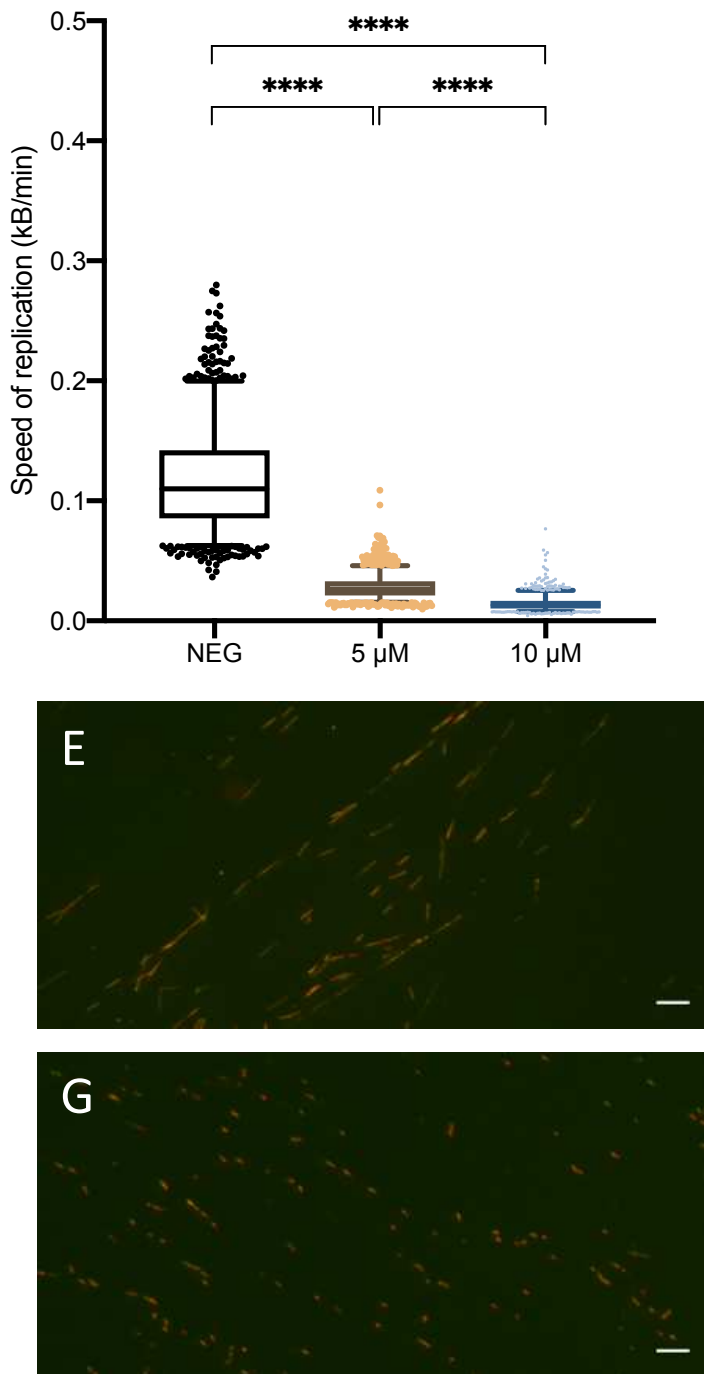

Figure 8: 1-(S, $\left.\boldsymbol{R}_{\boldsymbol{p}}\right)$ inhibits DNA-replication as assessed by single molecule DNA-fibre fluorography analysis. A) Experimental design: Cells were seeded at a density of $3 \times 10^{5}$ cells $/ \mathrm{mL}$ and allowed to attach for 24 hours before treatment with $\mathbf{1}-\left(\boldsymbol{S}, \boldsymbol{R}_{p}\right)(5,10$ and $25 \mu \mathrm{M})$ for 24 hours before labelling with CldU (red) and IdU (green) as described in the Materials and Methods. B) Total fibre length (red + green label) in kB and C) Replication

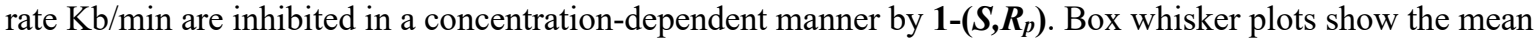
(horizontal bar), interquartile range (box) and 5 and 95 percentile range (whisker) with values outside that range plotted as individual points. The results represent the mean of three independent experiments $(n=3)$ with 1072 , 1406 and 1189 individual DNA-fibres analysed in control, 5 and $10 \mu \mathrm{M}$ treatments respectively. Treatment with $25 \mu \mathrm{M}$ 1-( $\left(\boldsymbol{S}, \boldsymbol{R}_{p}\right)$ resulted in complete inhibition of DNA-fibres which were not quantified. *** Statistically significant $(\mathrm{P}<0.0001)$ as assessed by a 1 -way ANOVA followed by a post-hoc Dunnett's T-test. Representative images from D) Control, E) $5 \mu \mathrm{M}$, F) $10 \mu \mathrm{M}$ and G) $25 \mu \mathrm{M}$ 1-( $\left.\boldsymbol{S}, \boldsymbol{R}_{p}\right)$ treated cells. Scale bar 10 $\mu \mathrm{m}$ and fibre length in $\mu \mathrm{m}$ was converted to $\mathrm{kB}$ of DNA as described in the Materials and Methods. 


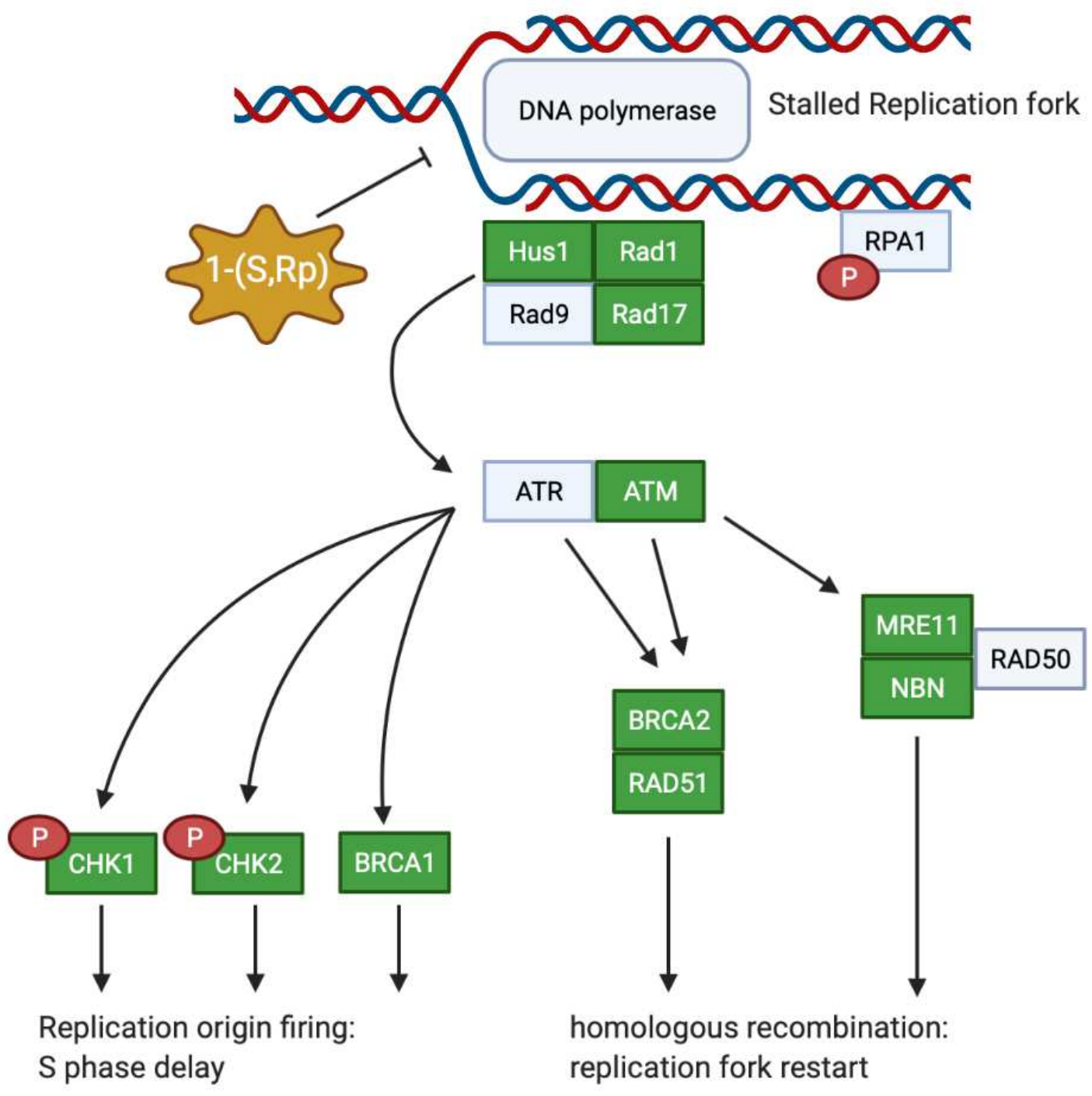

Figure 9: 1-(S, $\left.\boldsymbol{R}_{p}\right)$ stalls DNA-replication in pancreatic ductal adenoma carcinoma cells resulting in activation of downstream signalling pathways and replication fork arrest. Highlighted in green are genes of this pathway that are statistically significantly transcriptionally activated in response to treatment with $\mathbf{1}-\left(\boldsymbol{S}, \boldsymbol{R}_{p}\right)$. These include three out of the four genes involved in formation of the "9-1-1 checkpoint complex clamp" (HUS1, Rad1 and Rad17) and two out of the three genes that form the MRN complex (MRE11 and NBN). Also detected experimentally and shown as red circles was phosphorylation of RPA1 and both checkpoint kinases 1 and 2 . Diagram created in Biorender, www.biorender.com. 
Table 1: List of the top ten GO-terms functionally enriched in the network of 13 genes significantly over expressed in MIAPaCa2 and at least one other PDAC cell lines (BxPC3 and CFPAC-1) investigated.

\begin{tabular}{|l|l|l|}
\hline GO Term & GO description & FDR \\
\hline GO:0051726 & regulation of cell cycle & $8.16 \mathrm{e}-14$ \\
\hline GO:0007049 & cell cycle & $2.82 \mathrm{e}-9$ \\
\hline GO:0000079 & regulation of cyclin-dependent protein serine/threonine kinases & $4.89 \mathrm{e}-9$ \\
\hline GO:0045786 & negative regulation of the cell cycle & $4.65 \mathrm{e}-8$ \\
\hline GO:0010212 & response to ionizing radiation & $5.03 \mathrm{e}-8$ \\
\hline GO:1903047 & mitotic cell cycle process & $6.35 \mathrm{e}-8$ \\
\hline GO:0022402 & cell cycle process & $6.35 \mathrm{e}-8$ \\
\hline GO:0030330 & DNA damage response & $1.69 \mathrm{e}-7$ \\
\hline GO:0044773 & mitotic DNA damage checkpoint & $4.42 \mathrm{e}-7$ \\
\hline GO:0006259 & DNA metabolic process & $4.58 \mathrm{e}-7$ \\
\hline
\end{tabular}




\section{Supplementary Files}

This is a list of supplementary files associated with this preprint. Click to download.

- SupplementaryMethodsFiguresandTablesfinal220721.pdf 